\title{
Seismic site characterization of the Kastelli (Kissamos) Basin in northwest Crete (Greece): assessments using ambient noise recordings
}

\author{
M. Moisidi ${ }^{1,2} \cdot$ F. Vallianatos ${ }^{1} \cdot$ S. Kershaw $^{2} \cdot$ P. Collins $^{3}$ \\ ${ }^{1}$ Laboratory of Geophysics and Seismology, Department of Natural Resources and Environment, \\ Technological Educational Institute of Crete, 3 Romanou Str, Halepa, Chania, Crete 73133, Greece, \\ e-mail:moisidi@chania.teicrete.gr \\ ${ }^{2}$ Institute for the Environment, Brunel University, Uxbridge, Middlesex UB8 3PH, UK \\ ${ }^{3}$ School of Engineering and Design, Civil Engineering, Brunel University, Middlesex UB8 3PH, UK
}

\begin{abstract}
Crete is actively seismic and site response studies are needed for estimating local site conditions subjected to seismic activity. In order to collect basic data, we performed ambient noise recordings to estimate the site response of the surface and near subsurface structure of the small-scale Kastelli Basin in northwest Crete. The spatial HVSR resonance pattern of the investigated sites in the centre of the Basin consists of either one or two peaks divided into low to high frequency range in different sites as follows: a) in some sites only one amplified peak at low frequencies $(0.59-1.23 \mathrm{~Hz}), \mathrm{b})$ in other sites only one amplified peak at medium frequencies $(2.9-8.54 \mathrm{~Hz})$ and c) in yet other sites two amplified peaks in the low to high frequency range $(0.59-15.54 \mathrm{~Hz})$. The investigated sites are amplified in the frequency range $0.59-15.54 \mathrm{~Hz}$ while the amplitude reaches to a factor of 4 in the spectral ratios. The one HVSR amplified peak at low frequencies is related to locally soft or thick Quaternary deposits. Microtremors were measured in the coastal northwest part of the Basin in a well - lithified Cretaceous limestone site characterized by fractures and faults striking predominantly in a sector NNE to NNW. Sites of one amplified peak at medium frequencies are extended from coastal northwest to southwest delineating a structure striking to NNW. The two amplified peaks are attributed to shallow subsurface heterogeneities/irregularities, locally induced by fault zones and to the overlying Quaternary deposits. Spatial HVSR variations in the frequency and HVSR shape delineate four structures striking NNE, NNW and in a sector NW to WNW, crosscutting the dense populated Basin, suggesting that microtremors could be a valuable tool for providing a first approximation of fault zone delineation at least for the KastelliKissamos Basin. The Basin is classified into the X soil category of the Greek Seismic Code 2000.
\end{abstract}

Keywords Site effects, ambient seismic noise, HVSR, Kastelli-Kissamos Basin, northwest Crete

\section{Introduction}

It has been well-stated that local site conditions are capable of modifying ground seismic motion in the time and frequency domain and consequently contribute to earthquake damage distribution (e.g the example of Michoacán, 1985 earthquake in Mexico City). The contribution of local geotechnical characteristics to seismic motion, which has been evident by the consequences of past and recent destructive earthquakes worldwide (e.g the Loma Prieta, 1989 in California; Kobe, 1995 in Japan and the L'Aquila, 2009 earthquake in Italy) indicates the importance of site response evaluation studies in earthquake and geotechnical engineering disciplines.

This paper explores the analysis of microtremor recordings using the Horizontal to Vertical Spectral Ratios (HVSR) and aims to characterize the site response of the surface and shallow subsurface structure towards to the evaluation of the local site conditions. This work is the first site response 
evaluation study of Kastelli (Kissamos) Basin in northwestern Crete. HVSR and microtremors recordings have been applied to Kastelli Basin which is located in the forearc of the Wadati-Benioff zone of the southern Aegean region of Greece (Fig.1), considered one of the most seismically active parts of the Africa-Eurasia collision zone (e.g McKenzie 1978; Papazachos et al. 2000; Meier et al. 2007). The studied Basin in northwestern Crete has been selected due to the intense seismic activity that can occur in this area documented by co-seismic uplift of 6.5-7.9 m which has been associated with the 365 AD earthquake event (Pirazzoli et al. 1982, Stiros and Papageorgiou 2001). In the following sections we present a brief literature review, followed by description of the geological setting of the Basin and the adopted methodology. We present the spatial HVSR resonant pattern variability, the fundamental frequency map and the amplitude map, considered it as a lower representation of the amplification. Finally, we discuss the spatial variability of HVSR results and we present a further cross-correlation of the results with the available geological data with the additional geophysical survey data conducted to verify the existence of faults and a short literature review of published work in other case studies related to the research outcomes of this study.

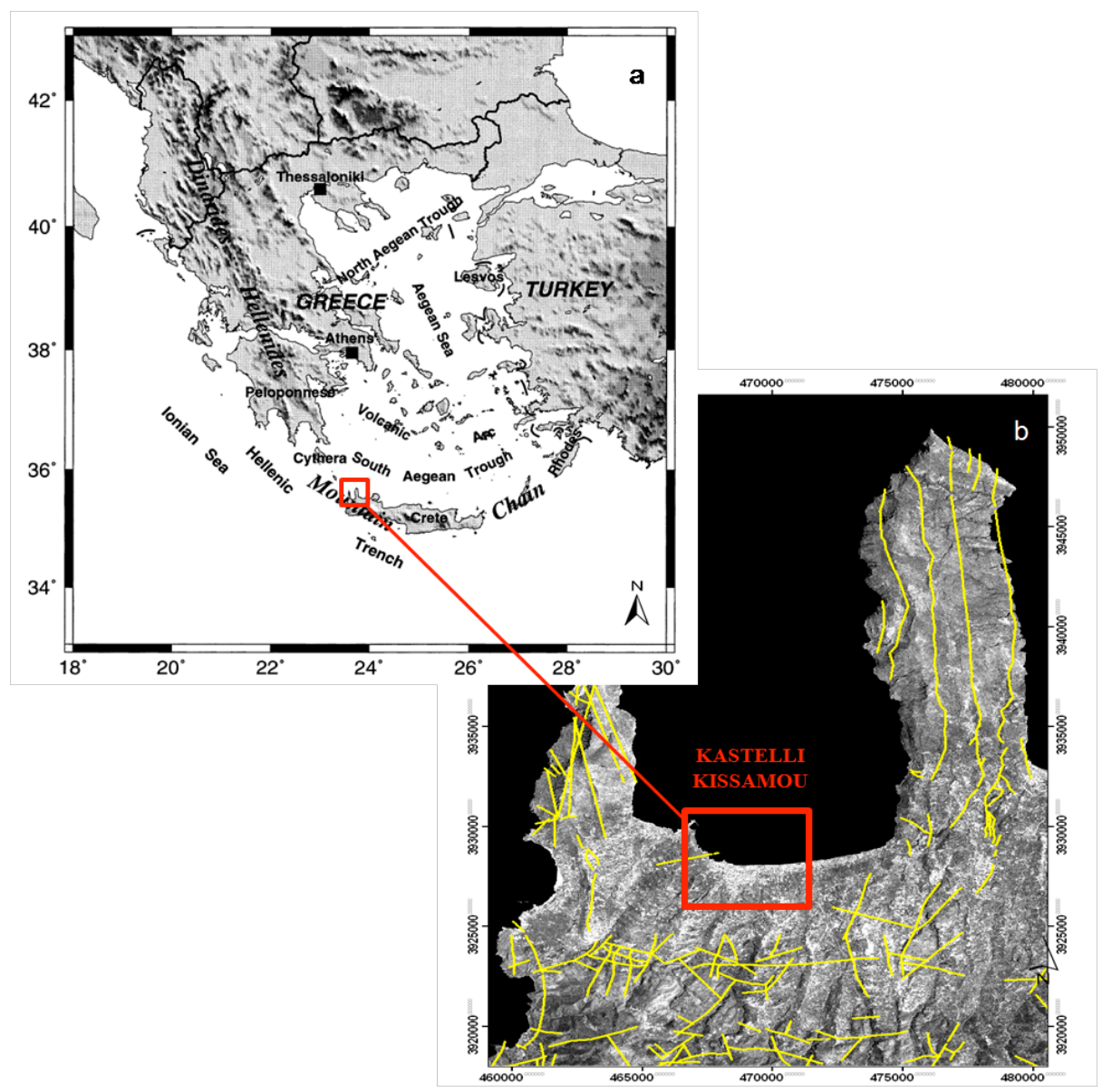

Fig. 1 a) The location of Crete in the outer arc of the Hellenic subduction zone (extracted and modified from Papazachos et al. 2000) b) Landsat satellite image of the Kastelli Basin (Kissamos, NW Crete) where the site response study conducted (red square). The yellow lines represent the identified faults (extracted from geological maps IGSR, 1970 and IGME, 2002) of Crete.

\section{Brief Literature Review}

Following recognition of the efficiency of the non-reference technique applied to ambient noise measurements for site characterization (Nogoshi and Igarashi 1971), the Horizontal to Vertical Spectra Ratio (HVSR) was presented by Nakamura (1989) and used to assess the local site conditions. The HVSR 
method has been used for site effects assessment in various geomorphological cases and microzonation studies (e.g Field et al. 1995; Chavez-Garcia et al. 1995; Teves-Costa et al. 1996; Bard 1998; Mucciarelli et al. 2003a; Cara et al. 2003; Bindi et al. 2009; Beroya et al. 2009; Gallipoli et al. 2011; Strollo et al. 2011; Puglia et al. 2011; Mucciarelli 2011). HVSR has been also applied in several Basins indicating the contribution of the local geomorphology on seismic ground motion (e.g Teves-Costa et al. 1996; Gueguen et al. 2000; Lebrun et al. 2001; Gosar 2007; Bonnefoy-Claudet et al. 2008; Özalaybey et al. 2011 ; Bindi et al. 2011).

Numerous site effects and microzonation studies have related the one HVSR peak in the low or high frequency with softness and/or thickness of the surficial deposits (e.g Teves-Costa et al. 1996; Fäh 1997; Mucciarelli and Monacheri 1998; Bour et al. 1998; Gueguen et al. 2007). Several of the site effects studies have related the two amplified HVSR peaks to the topmost layer and to the rest of the geological column (e.g Gueguen et al. 2000; Giampiccolo et al. 2001; Lebrun et al. 2001; Cornou et al. 2003; Di Giacomo et al. 2005; Oros 2009). HVSR applied to microtremors for the case study of Christchurch (New Zealand) revealed two amplified peaks corresponding to two resonant strata at different depths while the S-transform showed strong nonlinear effects (Mucciarelli 2011). The efficiency of HVSR in detecting the presence of trapped waves in fault gauges has been initially reported by Mucciarelli et al. (1999). HVSR and other spectral ratios techniques applied along or close to fault or fractures zones have revealed an amplified peak at medium to high frequencies while the results were locally cross-correlated with other experimental techniques or observational methodologies (e.g Lewis et al. 2005; Lombardo and Rigano 2006; Moisidi 2009; Marzorati et al. 2011; Coded et al. 2012; Moisidi et al. 2012).

Comparisons between HVSR applied to earthquake and ambient noise and other site effect techniques (e.g SSR, 1D TF and GIT) have shown agreement in the fundamental frequency while fluctuations in the amplification is evident suggesting a lower amplitude of HVSR (e.g Field and Jacob 1995; Parolai et al. 2004; Pilz et al. 2009; Ameri et al. 2011), compatible (e.g Horike et al. 2001; Rodriguez and Midorikawa 2002; Mucciarelli et al. 2003b; Di Giacomo et al. 2005) and at few cases higher (Nguyen et al. 2004; Teves-Costa et at.1996). A generalized outcome in terms of ground amplitude is that HVSR technique can be considered as a lower bound estimator of the amplification (Parolai and Richwalski 2004).

In alluvial Basins local site amplification effects can be in association with the impedance contrast of the sedimentary soft deposits overlying the bedrock and with the structural irregularities of complex 2D/3D sites, which can substantially modify the ground seismic motion. Comparisons between the HVSR and other experimental and numerical studies have suggested that the HVSR amplitude can be modified due to the amplification in the vertical component of seismic motion attributed to several factors (e.g Parolai and Rischwalshi 2004; Ameri et al. 2011; Bindi et al. 2011; Strollo et al. 2011). In cases involving sites near to source the low amplitude could be due to source to site geometry implying near vertical ray paths which induces large $P$ wave amplitude (Ameri et al. 2011).

\section{Geological setting}

The Kastelli Kissamos Basin is a small scale (2 km long in the EW and $1 \mathrm{~km}$ wide in the NS) alluvium-filled Basin with an approximate estimation of 3.900 permanent inhabitants. The geological map (IGSR, 1970) provides the only available published geological information for the Basin. The surface geology (Fig.1, IGSR, 1970) of the urban area of Kastelli-Kissamos Basin is composed of: 
a. Recent beach deposits and sand dunes (Holocene) in the vicinity of the coast (Quaternary).

b. Holocene alluvial deposits of loose loam, clay, sand and gravel of thickness not exceeding $3 \mathrm{~m}$ along the coast (Quaternary).

c. Pleistocene older fluvial terraces in the central and southern parts of the Basin (loose unconsolidated deposits of red brownish clays containing a large percentage of sand, granules and pebbles and sometimes boulders sourced from limestones, hornfels and rarely from flysch sandstone); some beds of the older fluvial terraces are alternating shales and argillaceous sandstones.

d. Marly limestones (compact brownish to yellowish) (Middle Miocene)

e. Marls (while and yellowish and at the deeper part greenish alternating with marly sanstones and banks of marly limestone; Gypsum (G) (Middle Miocene)

f. Conglomerates (pebbles mainly of Mesozoic limestones (Middle Miocene).

g. Flysch (alternating beds of shales and arqillacceous sandstones -Upper Cretaceous to Eocene).

h. Cretaceous limestones in the western part of the Basin (white to brown, locally compact lithographic thin bedded commonly fine grained or even microcrystalline in banks strongly karstified).

i. Cherts (red-brown seldom dark brown made up of alternating beds of radiolarites and shales with intercalations of red to blue-brown thin bedded limestone) in the southern mountainside of the Basin.

The urban area is surrounded by Holocene alluvial deposits in the vicinity of the coast, older fluvialterraces in the central part of the Basin, alluvial, fluvial and locally marly limestones, marls and conglomerates in the eastern part, Cretaceous limestone and flysch in the western part, while close to the mountainside marls, conglomerates, and cherts are evident. The cross-section A1-A2 (Fig. 2) indicates Pleistocene older fluvial deposits of varying thickness from surface till approximately $200 \mathrm{~m}$ depth. Ground-truthed evidence northwest of the coast in well-lithified Cretaceous limestone indicated a complex of multi-fractured network of joints and fault zones striking predominantly in a sector NNE to NNW (Fig.3). 


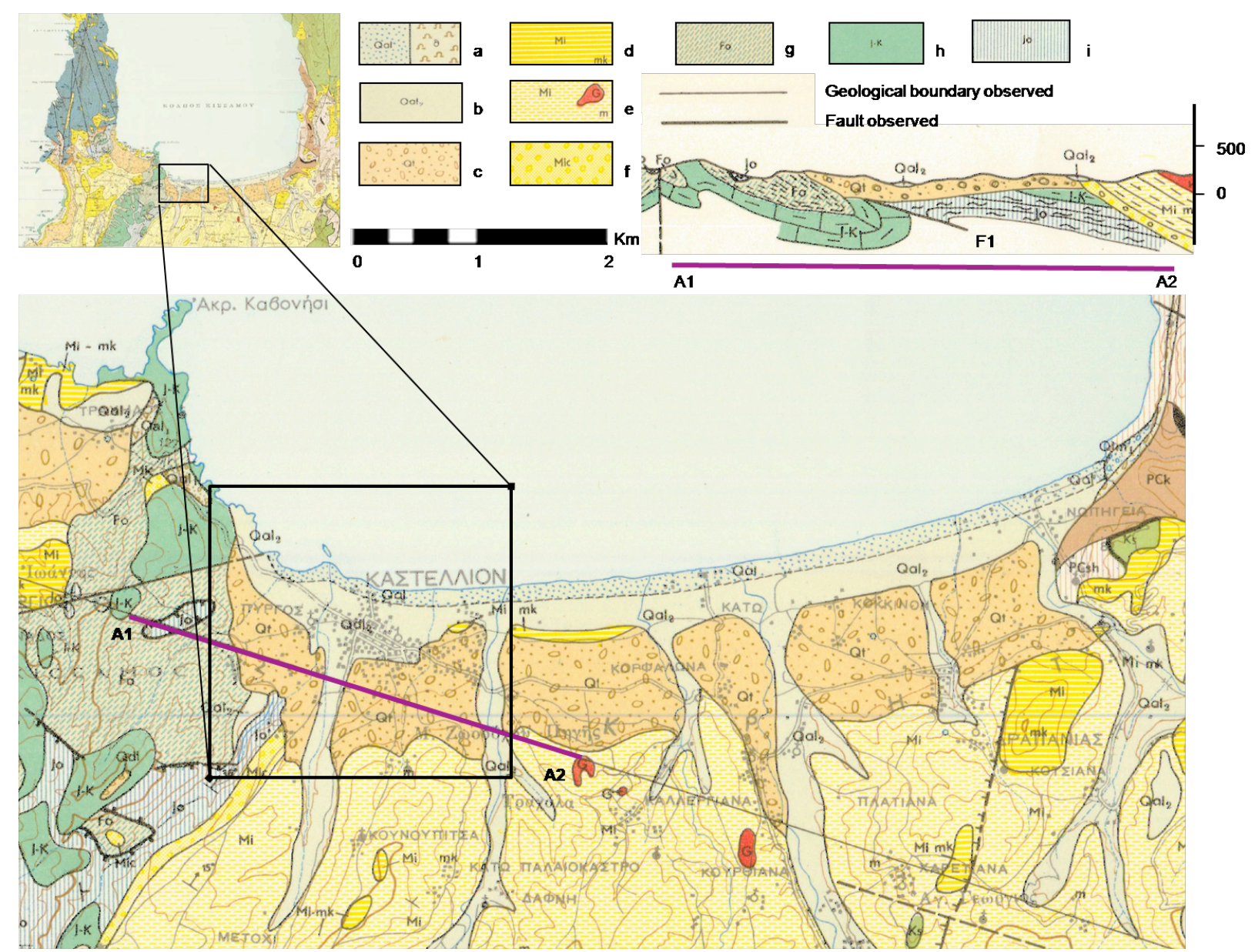

Fig.2 Map of the geology of Kissamos Basin in northwestern Crete. The map is extracted from the hard copy of the 1:50.000 scale map presented by IGSR (1970). The square indicates the broader area of Kastelli-Kissamos Basin where microtremors conducted. The surface geology of Kastelli-Kissamos Basin is characterized by: a) Recent beach deposits and sand dunes), b) alluvial deposits of loose loams, clays, sands and gravel, c) Pleistocene older fluvial-terraces, d) Marly limestones, e) Marls, f) Conglomerates, g) Flysch, h) Cretaceous limestones, i) Cherts. The cross-section A1A2 shown with magenta color on the map is a segment of a WNW-ESE cross-section of the geological column and is added in the map to provide an indication of the geological column variations at depth (upper right). In the cross-section A1-A2 (upper right) the inferred thrust fault that lies beneath the alluvial deposits is labelled F1 for the comparison with the HVSR outcomes 

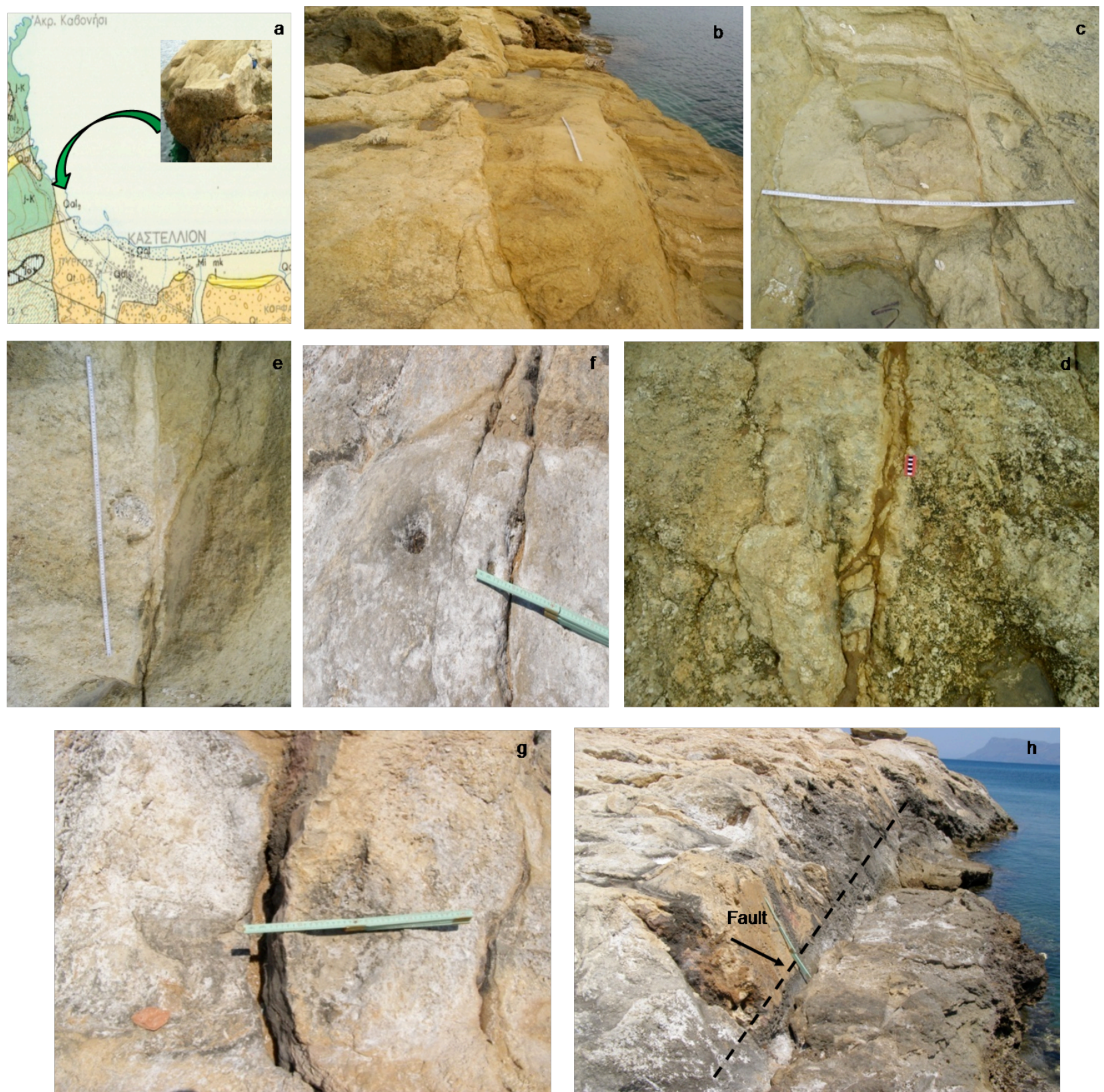

Fig.3 a) The site of geological evidence of fractures and faults in a well-lithified Cretaceous limestone located coastal northwestern of Kastelli-Kissamos Basin, (b-g) samples of fractures of irregular joint spacing (closed and opened joints of 2-12 cm spacing) and, (h) a fault in the coast in the well-lithified Cretaceous limestone site. At that site coastal of Kastelli the network of fractured and fault zones are striking predominantly in a sector NNE to NNW. The $1 \mathrm{~m}$ and the $20 \mathrm{~cm}$ meter rulers are used as a scale

\section{Methodology and data set}

The Nakamura (1989) method is based on the spectral ratio of horizontal to vertical (HVSR) components of microtremors recorded on surface ground using one single seismological station considering that the vertical component is not amplified by the surficial layers. The derived HVSR peak frequency is related to the fundamental frequency and the HVSR amplitude is related to the amplification of the investigated site (Nakamura 1996, 2000), while the relationship between fundamental resonance frequency, thickness and S-wave velocity of sedimentary deposits $\left(F_{0}=V s / 4 h\right)$ is also given by Nakamura $(1996,2000)$. Theoretical background and assumptions of the method are given in Nakamura $(1989,1996)$ and in the revised explanation (Nakamura, 2000). 
Microtremor recordings were collected using a single seismological station Lennartz 3D/5sec seismometer connected with Cityshark II acquisition system. The microtremor measurements were performed in good weather conditions not on windy days (Mucciarelli, 1998) or rainy days (Bard and Sesame WP12, 2004). To reduce any interference caused by wind the sensor was covered during the recording time (Mucciarelli et al. 2005). A spatial grid of microtremor recordings sampled at $125 \mathrm{~Hz}$ is acquired covering the populated and small scale (2 km in the EW $\times 1 \mathrm{~km}$ in the NS direction) Basin (Fig.6). Each of the $50 \mathrm{sec}$ non-overlapping signal time windows was corrected for baseline and for anomalous trends, tapered with a 5 per cent cosine function and band bass filtered from 0.2 to $20 \mathrm{~Hz}$. The amplitude spectra were smoothed using the Konno - Ohmachi window ( $b=20)$, (Konno and Ohmachi, 1998). The H/V spectra ratio for each time window has been derived by the division of the smoothed geometric mean of the two horizontal components over the vertical component. The $\mathrm{H} / \mathrm{V}$ ratios of the selected windows were averaged and the average HVSR spectra ratio, the $\mathrm{H}_{\mathrm{NS}} / \mathrm{V}$ and the $\mathrm{H}_{\mathrm{EW}} / \mathrm{V}$ ratios of the selected time series window and their standard deviation estimates of spectral ratios were calculated.

\section{Results}

The spatial HVSR resonance pattern of the investigated sites in the centre of the Basin consists of either one or two peaks divided into low to high frequency range in different sites as follows: a) in some sites only one amplified peak at low frequencies $(0.59-1.23 \mathrm{~Hz}), \mathrm{b})$ in other sites only one amplified peak at medium frequencies $(2.9-8.54 \mathrm{~Hz})$ and $\mathrm{c})$ in yet other sites two amplified peaks in the low to high frequency range $(0.59-15.54 \mathrm{~Hz})$. Examples of the observed typologies of HVSR, Hns/V and Hew/V ratios of microtremors are presented in Figure 4. Examples of microtremors recorded along joints/fault zones northwestern coastal of Kastelli (Fig. 3) in a well lithified Cretaceous limestone site and their HVSR spectra characteristics are presented in Figure 5. Figure 6 presents the sites of microtremor recordings and the spatial frequency classification map. In Figure 6: sites of microtremor recordings presenting one amplified peak at low frequencies are indicated with green circles; sites which present one amplified at medium frequencies are shown with red circles; while the sites presenting two amplified peaks in low to high frequency range are indicated with orange circles. Figure 7 shows the fundamental frequency map. The HVSR amplitude map is presented in Figure 8. The HVSR amplified peaks range between $0.59 \mathrm{~Hz}$ to $15.54 \mathrm{~Hz}$. The HVSR fundamental frequencies range between $0.59 \mathrm{~Hz}$ to $13 \mathrm{~Hz}$ (Fig. 7). The HVSR amplitude of the first amplified peak ranges from 1.59 - 3.99 (Fig. 8). Spatial HVSR variations of one amplified peak at medium frequencies and of two amplified peaks (at low and at medium or high frequencies) delineate four main structures striking NNW, NNE and in a sector NW to WNW (crosssections: $A B$ to $G H$ ) crosscutting the dense populated area (Fig.9 and Fig.10). The map of the frequency classification incorporated into the delineated structures, related to fault zones is presented in figure 10 .

The sites presenting one HVSR peak at low frequencies $(0.59-1.23 \mathrm{~Hz})$ are shown in Figure 6 with green circles (MK16, MK17, MK18, MK11, MK12 and MK31) and are dominated in the vicinity of the coast, in the southcentral and southeastern parts of the Basin. HVSR of one amplified peak at low frequencies $(0.59-1.23 \mathrm{~Hz})$ indicate sites of very soft or thick Quaternary deposits. In comparison with the geological map (Fig.2) those sites of one HVSR peak at low frequencies are associated with: recent beach deposits and sand dunes, Holocene alluvial deposits north of the Basin in the vicinity of the coast and with the thick Pleistocene older fluvial deposits in south-central and southeastern parts of the Basin (the section A1A2 on Fig. 2 indicates Pleistocene older fluvial deposits of varying thickness from the surface down to 
approximately $200 \mathrm{~m}$ below ground level). The amplitude of the one amplified HVSR peak at low frequencies is about $2.0(1.85-2.16)$.

Sites of one amplified peak at medium frequencies are located in the western part of the Basin (red circles on Fig.6). Microtremor measurements were conducted in the coastal northwest of the Basin in a complex multi-fractured well-lithified Cretaceous limestone site (Fig.3 and Fig.5). Examples of the sites (MK1-MK4) where microtremors recorded along ground-truthed joints/fault zones in the northwestern coastal area of Kastelli and their spectra characteristics are presented in Figure 5. HVSR using microtremors in the same area shows an amplified peak in the frequency range $3.06-3.69 \mathrm{~Hz}$ and the HVSR amplitude ranges between 1.79 to 2.53 (Fig.5). HVSR reveals one clear peak at medium frequency ( $F 0=3.69 \mathrm{~Hz}, A=2.53, M K 1$ ) along a segment of $10 \mathrm{~cm}$ fracture width (Fig $5 \mathrm{a}$ ). Sites MK2 and MK3 present one HVSR peak at medium frequency $(F 0=3.38 \mathrm{~Hz}, A=2.14$ shown in Fig.5b and $F 0=3.61 \mathrm{~Hz}, A=2.28$ shown in Fig.5c). One HVSR clear peak at frequency $3.06 \mathrm{~Hz}$ with amplitude 1.79 is observed at site MK4 (defined by a fault zone) in the well-lithified Cretaceous site without opened fractures. The higher HVSR amplitude $(A=2.53$, Fig.5a) is observed at site MK1 along a segment of a fractured zone of $10 \mathrm{~cm}$ wide compared to sites MK2 and MK3 ( $A=2.14$ and $A=2.28$ Figs.5b and $5 c)$ along fractured segments of closer fractured openings $(2-6 \mathrm{~cm})$, while the lower amplitude $(A=1.79$, Fig.5d) is observed at site MK4 without open joints.

The sites MK5 ( $F 0=2.9 \mathrm{~Hz}, A=2.04)$ and MK6 $(F 0=3.46 \mathrm{~Hz}, A=2.4)$ are located in the northwest of the Basin (red circles, Fig. 6), while the sites MK8 (F0=3.06 Hz, A=3.61), MK9 (FO=5.2 Hz, A=2.26) and MK10 (F0=5.2 Hz, A=3.2) are located southwest of the Basin (red circles, Fig. 6). Sites of one HVSR frequency at medium frequencies $(2.9-5.2 \mathrm{~Hz})$ are extended from northwestern to southwestern areas (sites MK1 to MK6 and MK8 to MK10, red circles, Fig. 9) delineating a structure striking almost NNW. Samples of the spatial HVSR variations along section AB west of Kastelli are presented in Figure 9. The HVSR amplitude along cross-section $A B$ ranges between 1.79 and 3.61. Site MK7 (Fig. 6) in the west of the Basin presents one HVSR peak at frequency $8.54 \mathrm{~Hz}$ with HVSR amplitude 3.47. The spectral characteristics of that site might attribute to the effects of thickness or stiffness of the older fluvial deposits or might be associated with the near fractured/fault zone heterogeneities effects related either to zone $A B$ or to fault zone GH (Figs.9 and 10).

Several sites present two amplified peaks (orange circles, Fig.6) indicating two resonant strata. Those sites are MK13, MK14, MK15, MK19, MK20 to MK30, MK32, MK33, MK34 and MK35 (Fig.6). The majority of the sites of two HVSR amplified peaks present the fundamental frequency at low frequencies and a second amplified peak at medium frequencies. For those sites the fundamental frequency at low frequencies ranges between $0.59 \mathrm{~Hz}$ to $0.99 \mathrm{~Hz}$, while the second amplified peak at medium frequencies ranges between $2.18 \mathrm{~Hz}$ to $7.19 \mathrm{~Hz}$. The HVSR amplitude of the first amplified peak (at frequencies 0.59 $\mathrm{Hz}$ to $0.99 \mathrm{~Hz}$ ) ranges from 1.59 to 2.24 (a mean value of 1.97) and the HVSR amplitude of the second amplified peak (at frequencies $2.18 \mathrm{~Hz}$ to $7.19 \mathrm{~Hz}$ ) ranges from 1.2 to 1.88 (a mean value of 1.42). The amplified peak at medium frequencies is related to the heterogeneities/irregularities of the near subsurface and the amplified low frequency to the thick or soft Quaternary (Pleistocene older fluvial terraces or Holocene alluvial) deposits overlying the shallow heterogeneities/irregularities of the structure.

The sites MK13, MK19 and MK25 present two amplified peaks at low and high frequencies. Site MK13 present the fundamental frequency at high frequencies $(F 0=12.28 \mathrm{~Hz})$ and a second amplified peak at low frequencies $(\mathrm{F} 1=1.55 \mathrm{~Hz})$. For site MK13 the HVSR amplitude of the fundamental frequency at 
$12.28 \mathrm{~Hz}$ is 2.23 and the amplitude of the second amplified peak at $1.55 \mathrm{~Hz}$ is 1.87 . The fundamental frequency of site MK13 at high frequencies is associated with the very shallow structure induced by heterogeneities and irregularities possibly related to the near fault zone either to zone $C D$ or to fault zone $\mathrm{GH}$. The second amplified peak at low frequency corresponds to locally thick or soft Quaternary deposits overlying the near subsurface heterogeneities. Sites MK19 and MK25 (located north and south along the section $C D$, Fig.10) present the fundamental frequency at low frequencies $(F 0=0.91 \mathrm{~Hz})$ and the second amplified peak at high frequencies $(14.83 \mathrm{~Hz}$ and $15.54 \mathrm{~Hz}$, respectively). For the site MK19 the HVSR amplitude of the fundamental low frequency is 1.95 and the HVSR amplitude of the second amplified peak at high frequency is 1.92 . For the site MK19 which is located north of the Basin the fundamental frequency at low frequencies is related to soft Quaternary deposits and the amplified peak in the high frequency range is associated with the very shallow structure. For the site MK25 the HVSR amplitude of the first amplified peak is 2.09 while the amplitude of the second amplified peak is 1.91 . The fundamental frequency at low frequency corresponds to thick older fluvial terraces. The second amplified peak in the high frequency range is associated with the very shallow structure possibly induced by heterogeneities and irregularities of the near subsurface. Samples of HVSR of two amplified peaks along cross-sections CD, EF and GH (Fig.10) are presented in Figure 9. 

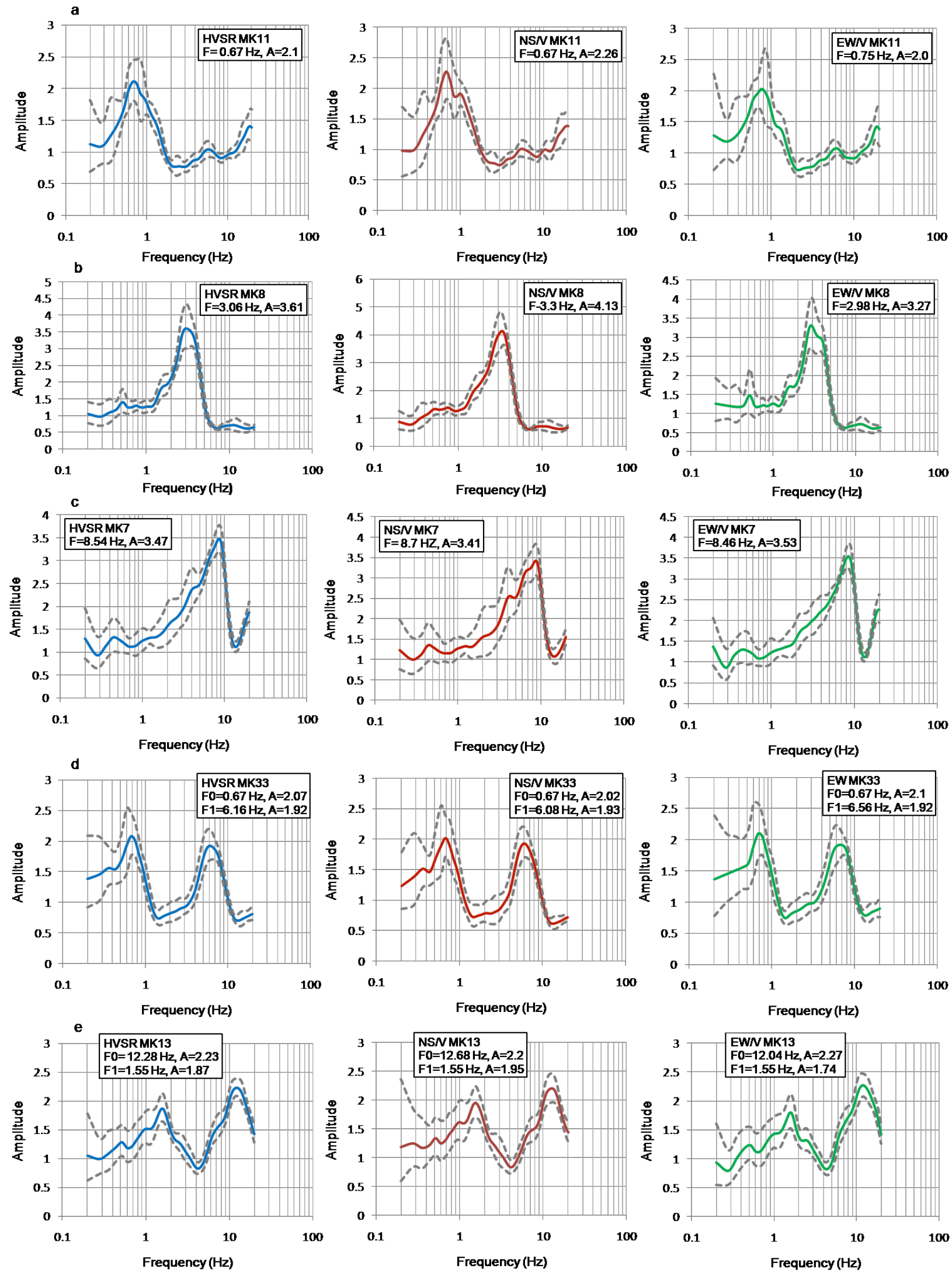

Fig.4 Typologies of HVSR, $\mathrm{H}_{\mathrm{ns}} / \mathrm{V}, \mathrm{H}_{\mathrm{ew}} / \mathrm{V}$ using microtremors for site effects evaluation in the centre of Kastelli-Kissamos Basin. a) one HVSR peak at low frequencies, b-c) one HVSR peak at medium frequencies, d-e) two amplified peaks. The horizontal scale of the HVSR curves represents the frequency range $(0.2-20 \mathrm{~Hz})$. The vertical scale represents the HVSR amplitude. The grey dashed lines correspond to the standard deviation of each $H / V, H_{n s} / V, H_{\text {ew }} / V$ curve. The blue line of the curves represents the average $\mathrm{H} / \mathrm{V}$ ratios of microtremor recordings. The red and green curves represent the Hns/V and Hew/V ratios, respectively 

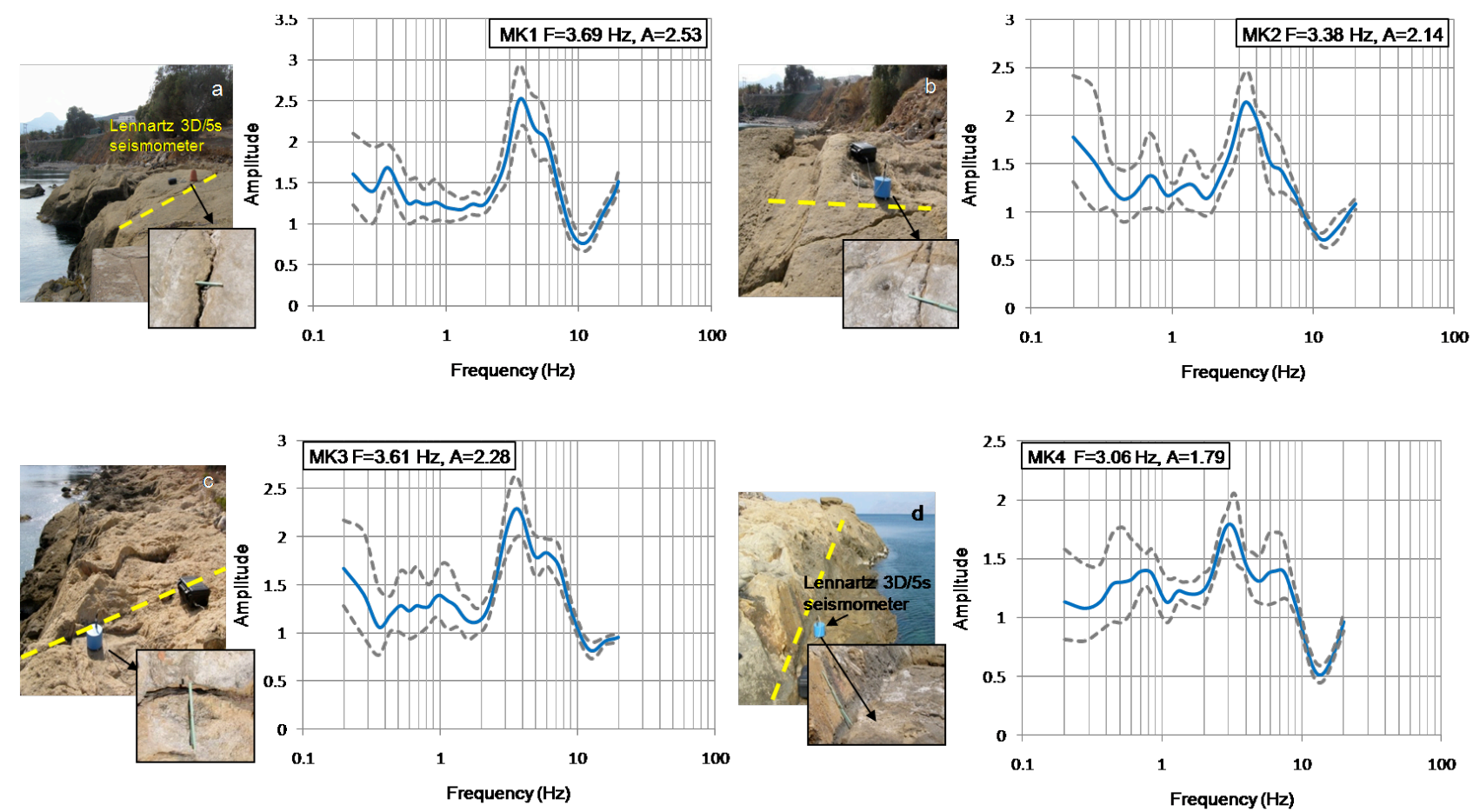

Fig.5 Examples of microtremors recordings and their spectra ratios along ground truthed joint sets and fault zones in a multi-fractured well-lithified limestone northwest of Kastelli. a) One HVSR clear peak at medium frequency ( $\mathrm{F} 0=3.69 \mathrm{~Hz}, \mathrm{~A}=2.53, \mathrm{MK} 1)$ along an segment of a joint opening of $10 \mathrm{~cm}, \mathrm{~b}$ and $\mathrm{c}$ ) one HVSR clear peak at medium frequency $(F 0=3.38 \mathrm{~Hz}, A=2.14, M K 2$ and $F 0=3.61 \mathrm{~Hz}, A=2.28, M K 3)$ at sites with joint opening of 2-6 cm, d) One HVSR clear peak at medium frequency ( $F 0=3.06 \mathrm{~Hz}, A=1.79$, MK4) along a fault in the well lithified limestone site. During the microtremor recording time the seismometer was well-covered to avoid wind perturbations as shown on site MK1. For each HVSR curve the blue line represents the average HVSR curve and the grey dashed lines the standard deviation of the average HVSR

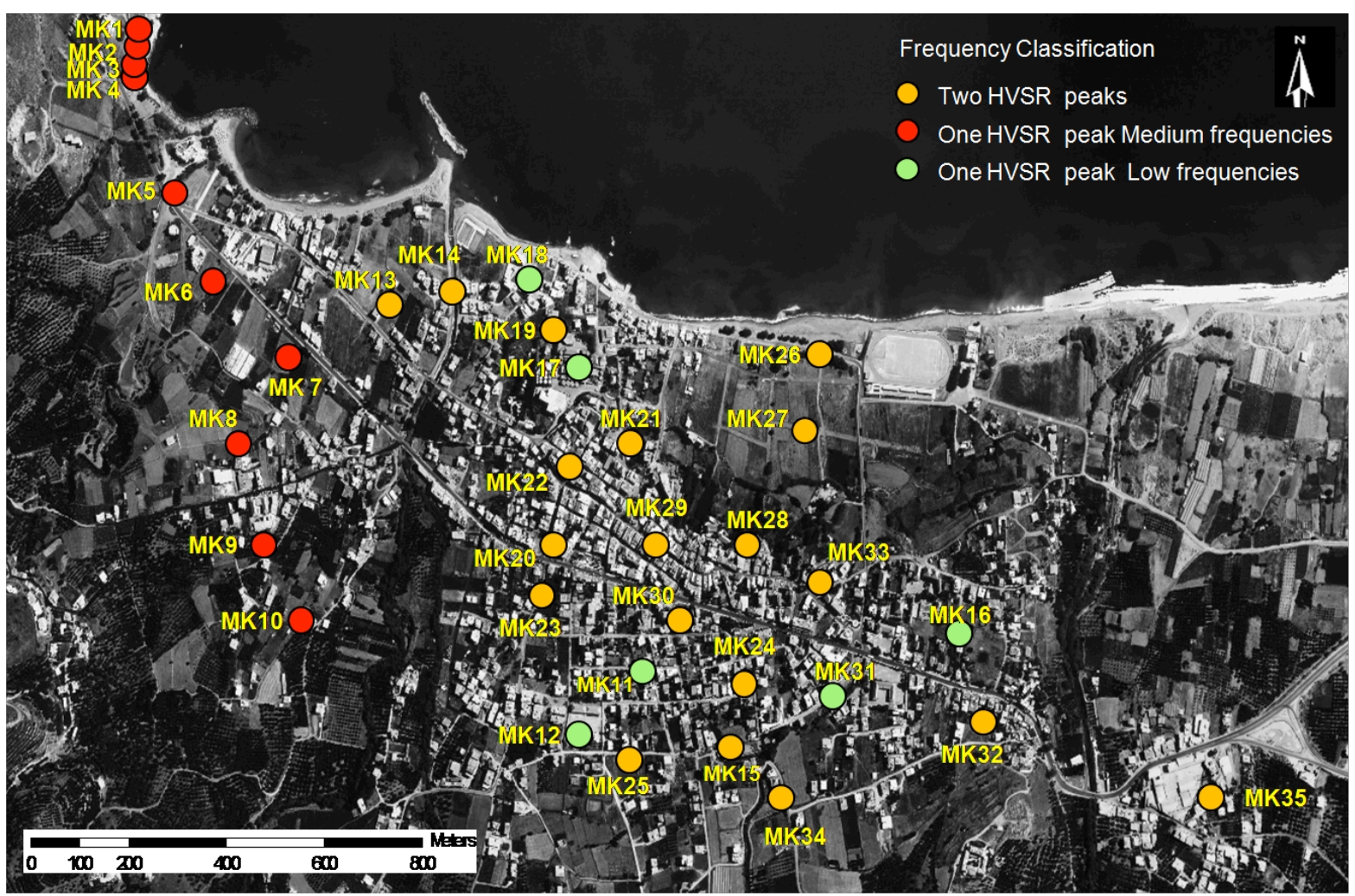

Fig.6 Spatial frequency classification map. The orange circles represent sites of two amplified peaks in the low to high frequency range. The green circles represent sites one amplified peak at low frequencies. The red circles represent sites of one amplified peak at medium frequencies. Note that the red circles are located west of the Basin and are spatially separated from others; the red circles could be interpreted to 
reflect to the effect of fractured solid bedrock near the surface. The green circles reflect to the soft or thick Quaternary deposits while the orange circles reflect to the near subsurface heterogeneities/irregularities and to the overlying Quaternary deposits. See Discussion section of this paper

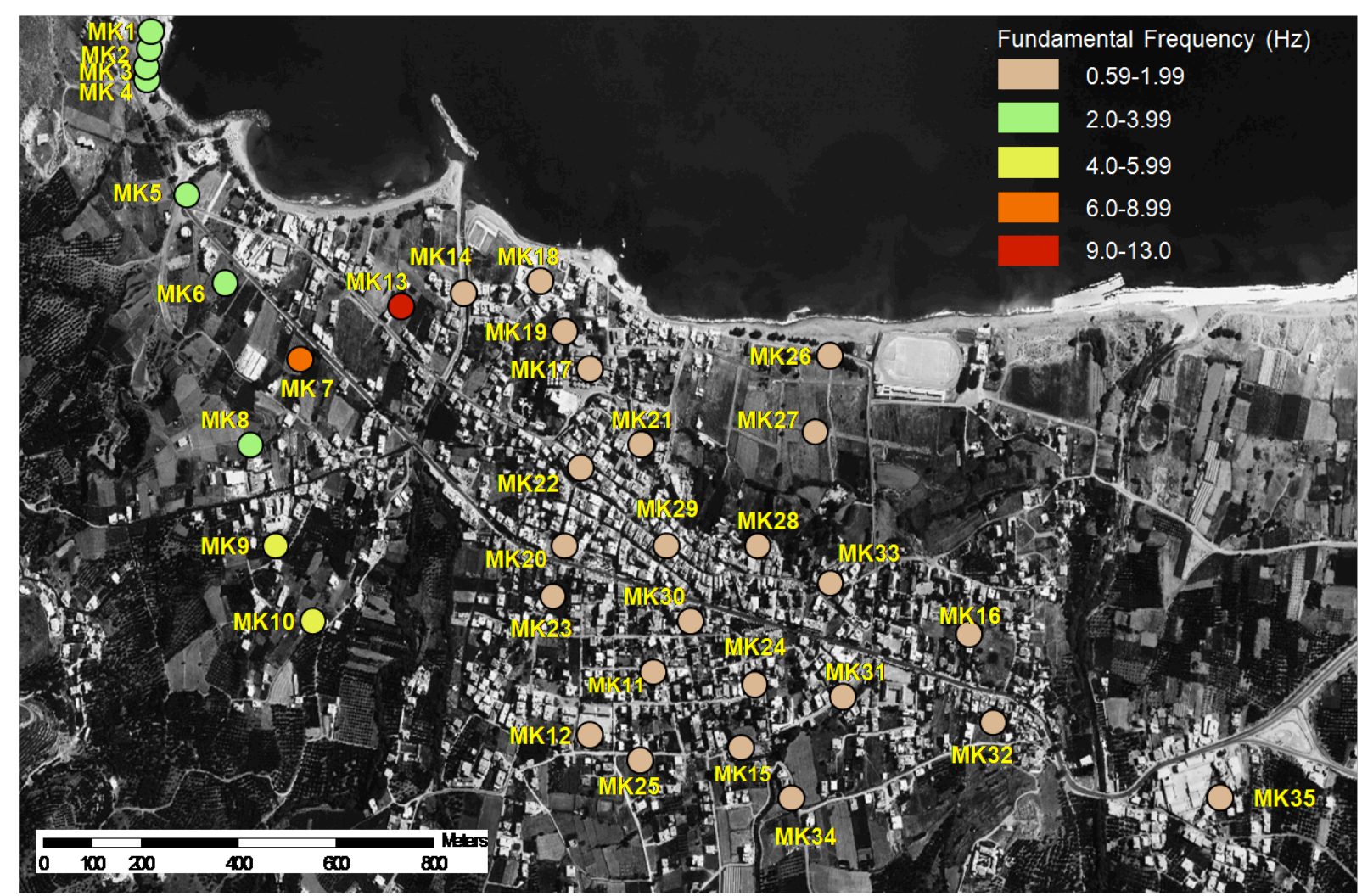

Fig.7 Spatial HVSR fundamental frequency distribution map. As in Fig.6, there is a spatial separation between the western border of the field area and the rest based on the fundamental frequency (first amplified peak) distribution. See Discussion section of this paper

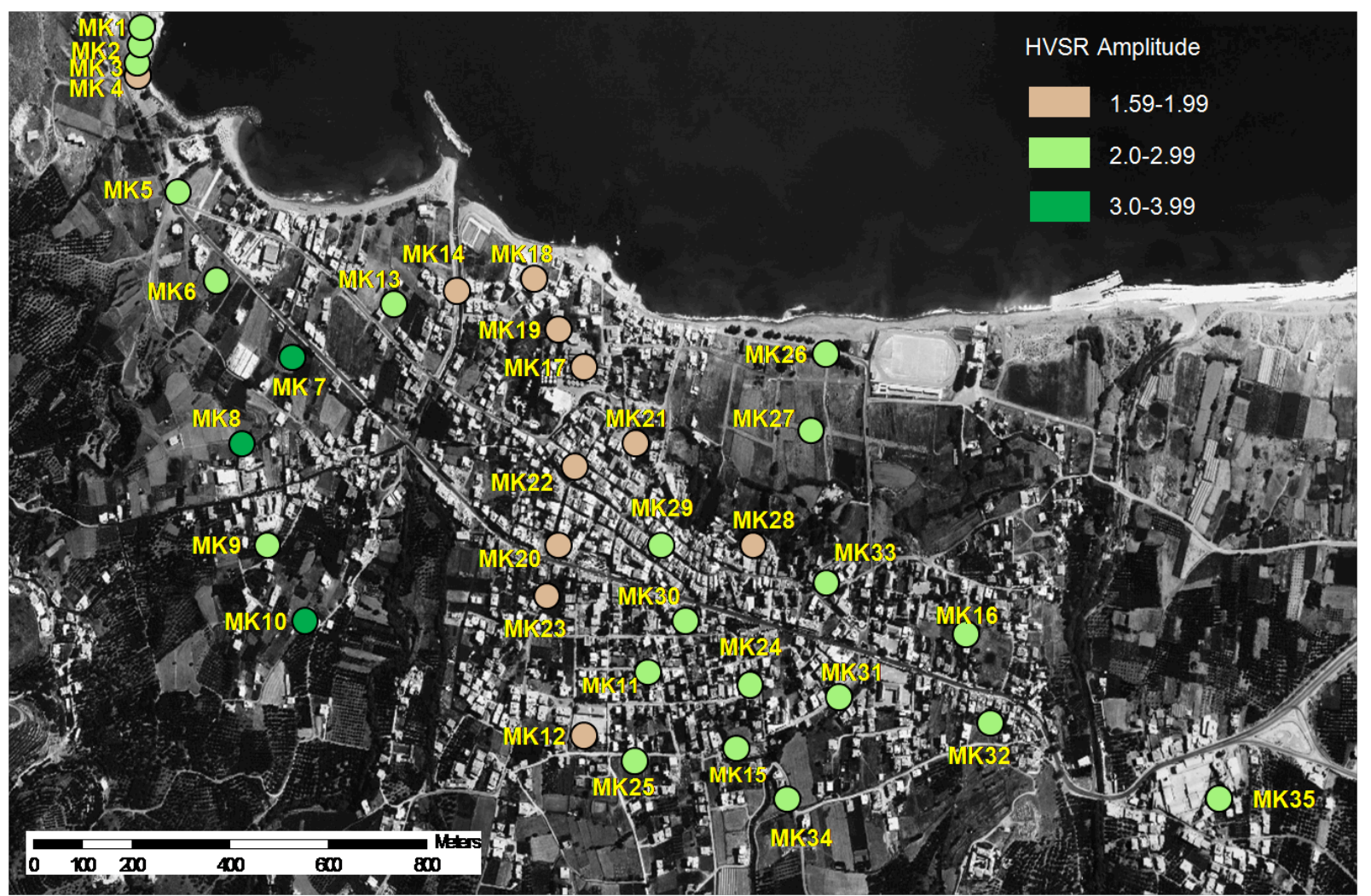

Fig.8 Spatial HVSR amplitude of the fundamental frequency distribution map. Brown circles indicates sites of HVSR amplitude of the fundamental frequency in the range 1.59-1.99. The green circles correspond to HVSR amplitude of the fundamental frequency in the range 2.0-2.99 and the dark green correspond to 
HVSR amplitude of the fundamental frequency in the range 3.0-3.99. The HVSR pattern suggests that the higher amplitude is observed in the western border of the field area. See Discussion section of this paper
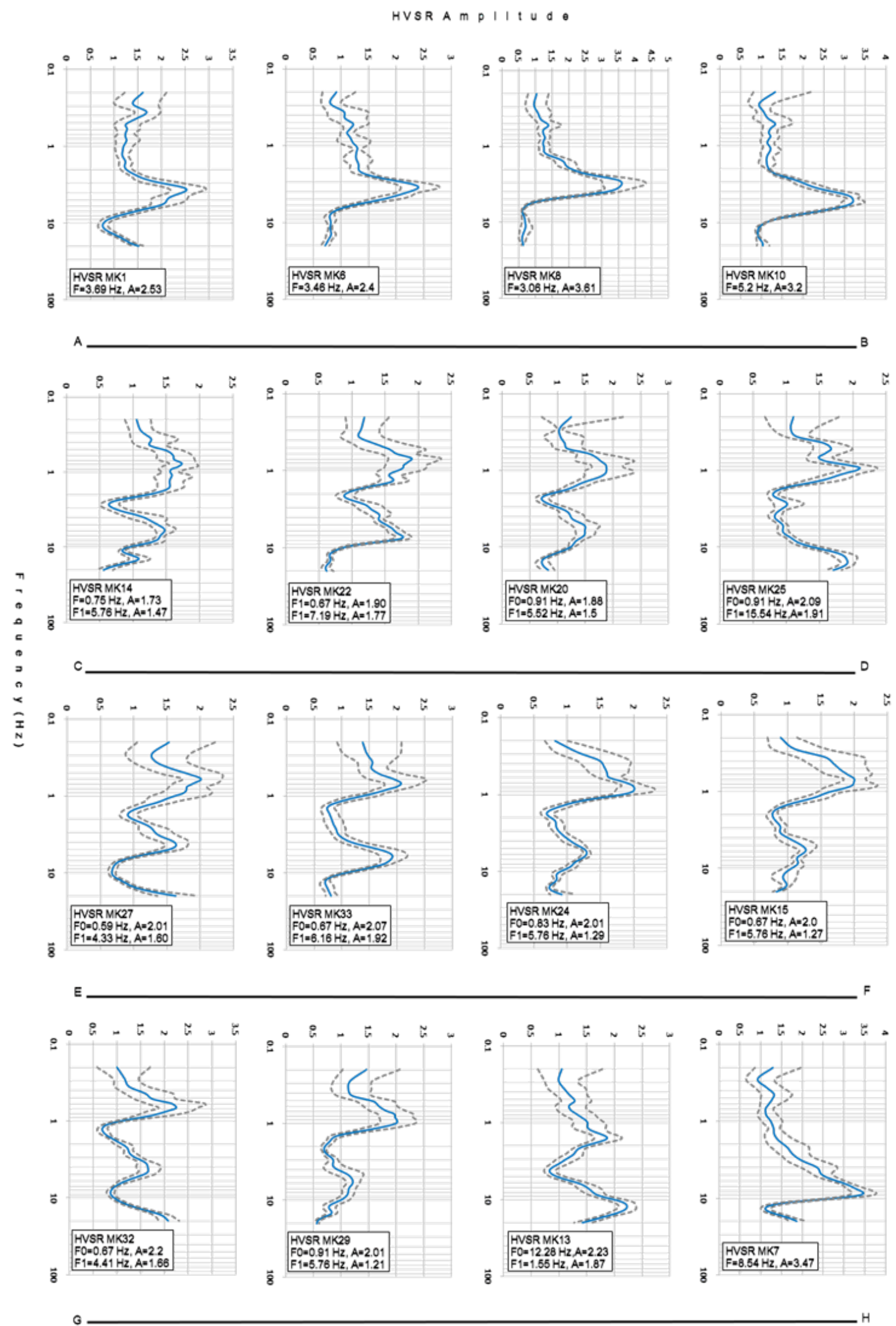

Fig.9 Samples of spatial HVSR variations and HVSR shape similarities along sections $A B, C D$, EF and $\mathrm{GH}$. Sample of sites west of the Basin (section AB) characterized of one amplified peak (Fig.6 red circles) at medium frequencies $(2.9-5.2 \mathrm{~Hz}$, Fig. 7 green and yellow circles). Sections CD and EF are characterized of two amplified peaks related to soft alluvial or thick older fluvial terraces and with the shallow heterogeneities/irregularities. Spatial HVSR variation is characterized of two amplified peaks at low 
and medium to high frequencies and of one amplified peak at medium frequency (for site MK7) along the section $\mathrm{GH}$

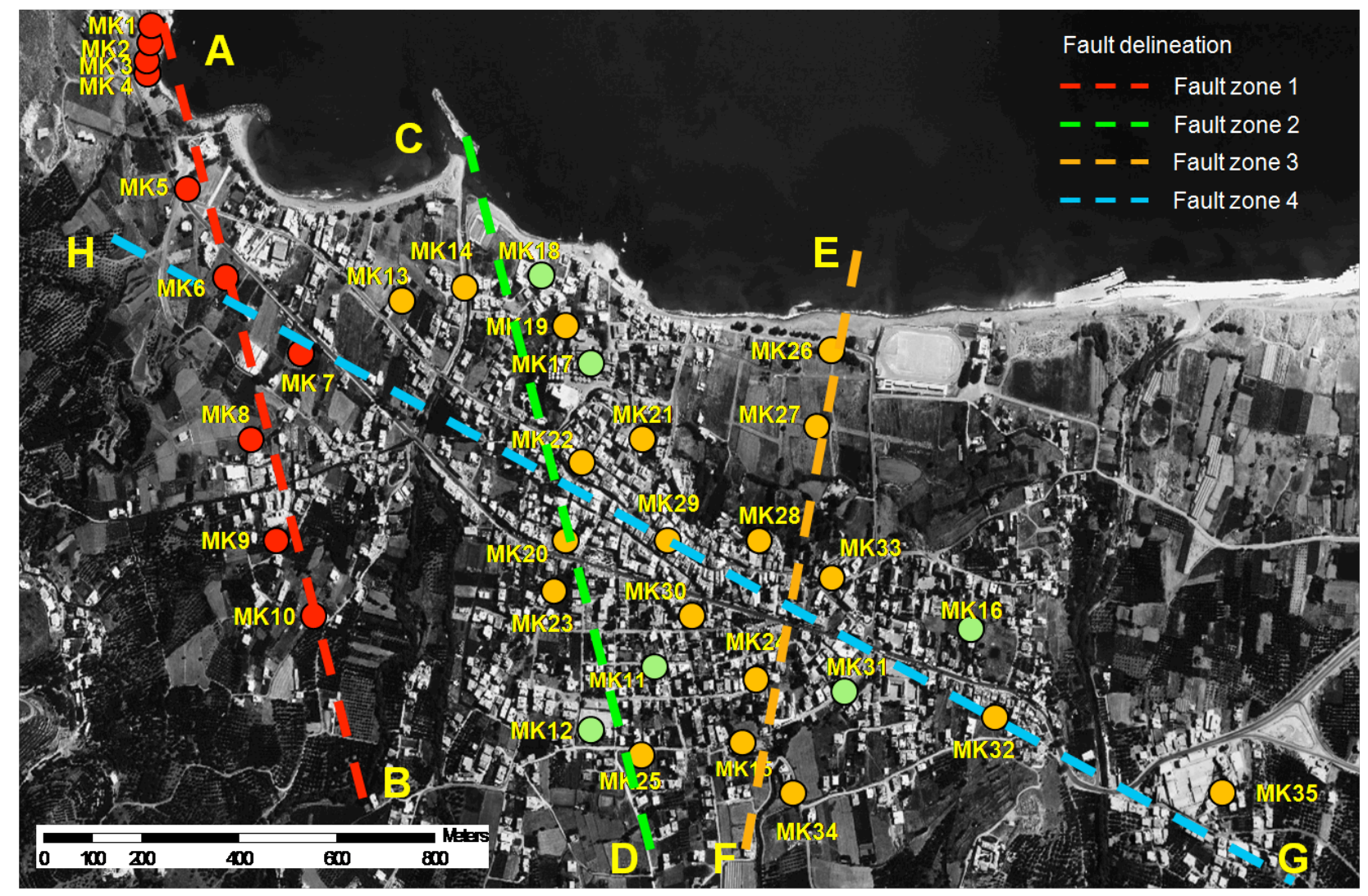

Fig.10 Map of the spatial HVSR variation and the delineated four structures zones interpreted as being related to fractured/fault zones crosscutting the dense populated area. One clear fundamental frequency at medium frequencies delineates a NNW-SSE zone (section AB, red dashed line) west of Kastelli. HVSR ratios of two amplified peaks delineate an almost NNW-SSE structure (section CD, green dashed line) in the central and an NNE-SSW zone in the eastern (section EF, orange dashed line) part of Kastelli. Section $\mathrm{GH}$ attributes to a structure striking NW to WNW-ESE (blue dashed line). See discussion section of this paper

\section{Discussion}

As shown in the result section, HVSR technique using microtremor measurements recorded in the centre of the Kastelli-Kissamos Basin revealed sites presenting spectral resonance pattern characterized by one amplified peak at low frequency in some sites, one amplified peak at medium frequency in other sites and of two amplified peaks in yet other sites. The variation is interpreted to be associated with the surface and shallow subsurface materials and structure.

The sites presenting one HVSR peak at low frequencies $(0.59-1.23 \mathrm{~Hz})$ are dominated in the vicinity of the coast, in the southcentral and southeastern parts of the Basin. The one HVSR amplified peak at low frequencies $(0.59-1.23 \mathrm{~Hz})$ indicates thick or soft Quaternary deposits (the relationship between fundamental resonance frequency, thickness and S-wave velocity of sedimentary deposits is given by Nakamura (2000) and the relationship between low HVSR frequencies and thick or soft surficial deposits is experimentally confirmed by several site effects studies, e.g Fäh et al. 1997). In comparison with the geological map (IGSR, 1970) sites of one amplified HVSR peak at low frequencies are associated with sites characterized by Holocene alluvial deposits (loose loams, clays not exceeding the $3 \mathrm{~m}$ thickness) and of Pleistocene older fluvial deposits (the section A1A2 on Fig. 2 suggests Pleistocene older fluvial deposits 
of varying thickness from the surface down to approximately $200 \mathrm{~m}$ below ground level - as shown by IGSR, 1970). The amplitude of the one amplified peak at low frequencies is about 2.0 (1.85 - 2.16) possibly related to sites characterized by either: i) local variations of the grade of consolidation at depth of the Holocene alluvial Quaternary deposits overlying unconsolidated Pleistocene older fluvial terraces forming a low impedance contrast, or ii) low impedance contrast of locally unconsolidated Pleistocene older fluvial terraces overlying thick and cemented/consolidated Pleistocene older fluvial terraces (thick fluvial with increasing the grade of sediments consolidation at depth).

In the northwest coastal area of Kastelli one clear HVSR amplified peak at medium frequencies $(3.06-3.69 \mathrm{~Hz}$ ) with amplitude 1.79 to 2.53 (Fig. 9) is observed along a complex multi-fractured welllithified Cretaceous limestone site characterized by fractures and faults striking predominantly in a sector NNE and NNW (Figs. 3 and 5). The higher HVSR amplitude $(A=2.53)$ is observed along a segment of a fractured zone of width $10 \mathrm{~cm}$ (Fig. 5a), a lower amplification is observed along a fractured segment of closer joint opening $(A=2.14$ and $A=2.28)$ while the lower amplification level $(A=1.79)$ is observed along a site located in the fractured well-lithified Cretaceous limestone site but without open joints (Fig.5d). Regarding the correlation of frequency and amplification level with the fracture opening similar considerations have been proposed by Marzorati et al. (2011) using HVSR in Castelvecchio Subequo village (L'Aquila, Italy). Marzorati et al. (2011) correlated the seismic amplification (at two sites slightly higher than 2.0) in the frequency range $1-8 \mathrm{~Hz}$ (the larger amplification was found at frequencies $3-4$ $\mathrm{Hz}$ ) with the fracture opening (the fractures have irregular spacing from tens of $\mathrm{cm}$ to meters) and observed no or low amplification at sites where the bedrock is densely fractured but with no open joints. Volant et al. (2002) in a study aimed to seismic evaluation of an existing nuclear facility (SE France) found HVSR fundamental frequency at frequencies of $1.5-2.0 \mathrm{~Hz}$ and amplification lower than 2 at a fractured limestone site. Both the comparative studies showed that along a fracture limestone site HVSR fundamental frequency was found in the range $1-8 \mathrm{~Hz}$ (Marzorati et al. 2011) and $1.5-2.0 \mathrm{~Hz}$ (Volant et al. 2002) and at selected sites low amplification (lower than 2.0 or slightly higher than 2.0) was observed. In addition, the research outcomes of work by Marzorati et al. (2011) indicated (in conjunction to results from Kastelli-Kissamos Basin) that: a) the amplification is related to joint opening, highlighting that no or low amplification is observed at sites where the limestone bedrock is densely fractured but with no open joints, b) the larger amplification was observed along sites of open joints, c) the HVSR frequency along fractured limestone site was observed in the range $1-8 \mathrm{~Hz}$, whereas the larger amplification was found in the frequency range $3-4 \mathrm{~Hz}$. For the Kastelli-Kissamos Basin the HVSR study in a fractured limestone site showed that: a) the lower amplification $(A=1.79)$ was observed along a site with no open joints (site MK4, Fig.5), b) the higher amplification ( $A=2.53$ ) was observed along a site with open joints (joint opening of $\sim 10$ $\mathrm{cm}$, site MK1, Fig. 5), c) the HVSR frequency along the multi-fractured well-lithified Cretaceous site northwest of the Basin is found in the frequency range $3.06-3.69 \mathrm{~Hz}$. In conclusion, we can infer that the observed HVSR peak at medium frequencies in the west of the Basin occur in a fractured well-lithified limestone site (a well-lithified limestone site which is likely to be fractured during folding and thrusting). In a whole, the above studies characterized by fractured limestone bedrock sites, indicated that the HVSR amplification is related to the opening of the joints and the HVSR amplified peak is observed at medium frequencies in a fractured limestone site.

For the case study of Kastelli-Kissamos Basin sites of one clear HVSR fundamental frequency at medium frequencies (Fig.6) are extended from coastal northwest area $(3.06-3.69 \mathrm{~Hz})$ - where ground 
truth evidence in a well lithified Cretaceous sites characterized by multi-fractured and fault zones (Fig.3) to the southwest area $(2.9-5.2 \mathrm{~Hz})$ delineating a structure striking to almost NNW-SSE. We suggest that the one HVSR fundamental frequency at medium frequencies extended from coastal northwest to southwest might be related to the near surface heterogeneities/discontinuities induced by the effect of a fractured/fault zone striking to almost NNW-SSE (Fig.9 and Fig.10, section AB). That zone might be also associated with the fault indicated as F1 in the cross-section A1A2 (Fig.2) shown on the geological map (ISGR, 1970). The HVSR amplitude of the one amplified peak at medium frequencies $(2.9-5.2 \mathrm{~Hz})$ southwest of the Basin ranges between 2.04 to 3.61 (Fig.8). West of the Basin the site MK7 (Fig.6) presents an amplified HVSR peak at $8.54 \mathrm{~Hz}$ with amplitude 3.47 , possible associated to near surface heterogeneities induced either to fractured/fault zone $A B$ or to fault zone GH (Fig.10). Recently, Coded et al. (2012) using HVSR and 1D numerical method suggested that the observed frequency at $2.5 \mathrm{~Hz}$ at a site in Malaga city (Southern Spain) might be related to a fault zone. Mucciarelli et al (2011) studied the earthquake damage on a reinforced concrete building in San Gregorio (L'Aquila, Italy) and found close to the collapsed building a clear soil HVSR resonance peak at $2.6 \mathrm{~Hz}$ (of high amplitude) at a site located near to the alignment of co-seismic ground fractures of the Miocene calcarenites (while flat HVSR patterns were observed far from the collapsed building on outcropping well-cemented Miocene calcarenites). Calderoni et al. (2010) found larger amplitude at a seismological station installed on a segment of a fault system compared to nearby stations of the L'Aquila earthquake (central Italy) and observed that spectral ratios using earthquakes resulted in a varying amplitude at frequencies $1-8 \mathrm{~Hz}$ at a seismological station located on a fault zone. Roten et al. (2008) observed clear HVSR peaks in the frequency range $3.5-8 \mathrm{~Hz}$ at sites located near the eastern master fault, between Weil and Lorrach in the Rhône valley (Switzerland). Lombardo and Rigano (2006) observed significant ground amplification at frequencies $4.0-8.0 \mathrm{~Hz}$ at sites located close to the Tremestieri fault (Mt. Etna, Italy). Summarizing, the research outcomes of those studies suggest that along fractured and/or fault zones which are located in various geographical locations the spectral ratios showed peaks in the frequency range $1-8 \mathrm{~Hz}$. Specifically, the spectral ratios along or close to fractured/fault zones showed peaks: at frequencies $4.0-8.0 \mathrm{~Hz}$ (Lombardo and Rigano, 2006) in Italy, in the frequency range $3.5-8 \mathrm{~Hz}$ (Roten et al. 2008) in Switzerland, at frequencies $1-8 \mathrm{~Hz}$ (Calderoni et al. 2010) in central Italy, at frequency $2.6 \mathrm{~Hz}$ (Mucciarelli et al. 2011) in San Gregorio (L'Aquila,Italy), at frequency of $2.5 \mathrm{~Hz}$ (Coded et al, 2012) in southern Spain and in the frequency range $2.9-8.54 \mathrm{~Hz}$ for the Kastelli-Kissamos (this study) in northwest Crete.

For the Kastelli Basin sites of two amplified HVSR peak at low and medium or at low and high frequencies indicate two resonant strata. Sites of two amplified peaks are associated with the heterogeneities/discontinuities effects of the near subsurface structure possible induced by a fractured/fault zone not directly observable at the surface and with the overlying Quaternary deposits. The majority of sites present the fundamental frequency at low frequencies $(0.59-0.99 \mathrm{~Hz})$ and the second amplified peak at medium frequencies $(2.18-7.19 \mathrm{~Hz})$. The amplified peak at medium or high frequencies (2.18 - $7.19 \mathrm{~Hz}, 12.28 \mathrm{~Hz}, 14.83 \mathrm{~Hz}$ and $15.54 \mathrm{~Hz}$ ) is interpreted here as being related to the heterogeneities/irregularities of the near subsurface structure locally induced by fault zones and the amplified low frequency $(0.59-1.55 \mathrm{~Hz})$ to the thick or soft Quaternary (Pleistocene older fluvial terraces or Holocene alluvial) deposits overlying the near heterogeneities/irregularities of the structure. Samples of the spatial HVSR variations along cross-sections CD, EF and GH in the center of the Basin are presented in figure 9. Sites of two HVSR peaks, with the one amplified peak at medium or high frequency and the 
other one at low frequency delineated three main structures possible related to fractured/fault zones (CD, EF and GH on Fig.10) striking NNW (CD zone), NS to NNE (EF zone) and NW to WNW (GH zone).

Our results are in agreement with Lombardo and Rigano (2006) who used HVSR technique and microtremors across the Tremestieri fault and an eruptive fracture and found two amplified peaks in the range $(1.5-2.0 \mathrm{~Hz})$ and $(4.0-8.0 \mathrm{~Hz})$. Cross-comparison of HVSR and ERT profiles along Pahia Ammos of the Paleohora Basin in southwest Crete suggested that the two clear HVSR peaks in the medium to high frequencies $(4.4-11.65 \mathrm{~Hz})$ and at low frequencies $(0.75-1.3 \mathrm{~Hz})$ are related with the shallow lateral heterogeneities induced by an E-W fault zone of $80 \mathrm{~m}$ width at a depth of at least $80 \mathrm{~m}$ and with the Quaternary alluvium deposits overlying the lateral heterogeneities (Moisidi 2009; Moisidi et al. 2012). In this case study spatial variation of microtremors perpendicular to the fault zone was capable to delineate a near subsurface E-W fault zone.

Our results from the Kastelli Basin show that several of the sites of two amplified peaks present relatively low HVSR amplitudes (lower than 2.0 and about a value of 2.0). For the sites presenting two amplified peaks, the HVSR amplitude of the amplified peak at low $(0.59-1.55 \mathrm{~Hz})$ frequencies (related to the overlying Quaternary deposits) is ranging from 1.59- 2.24 (a mean value of 1.97) while the amplitude of the second amplified peak at medium to high $(2.18-15.54 \mathrm{~Hz}$ ) frequencies (which are related to the near heterogeneities/irregularities and to fault zone delineation) is ranging from 1.2-2.23 (a mean value of 1.51). Samples of the spatial spectral variability along the microtremor profile perpendicular to the E-W fault zone in Pahia Ammos of the Paleohora Basin suggested that the HVSR amplitude in the medium to high frequencies $(4.4-11.65 \mathrm{~Hz}$ ) ranged from approximately 1.4 to 2.5 (Moisidi 2009; Moisidi et al. 2012). Lewis et al. (2005) using microseismicity data from temporary stations along three fault branches of the San Jacinto fault zone (California) of $\sim$ width $100 \mathrm{~m}$ and calculating the spectral ratios of the each fault seismogram observed that the concentration of spectral energy between about $2 \mathrm{~Hz}-10 \mathrm{~Hz}$ is associated with fault zone trapped waves. The calculated spectral ratios (Lewis et al. 2005) at stations installed parallel to fault zone were higher (a mean value of 1.68) than those spectral ratios derived from stations installed perpendicular to the fault zone (a mean value of 1.50 and 1.53) which suggests that the trapping efficiency is different for each fault branch.

For the Kastelli Basin the spatial spectral variations of microtremor delineated four speculated fault zones. To image the near subsurface structure and to verify the presence of fault zones electrical resistivity tomography (ERT) survey using Wenner-Schlumberger arrays were conducted in the coast northwest and northeast of Kastelli Basin (Moisidi et al. 2013). Two ERTs were conducted perpendicular to the cross-sections HG and EF (Fig.11). The reader is referred to the two ERT profiles (figs. $7 \mathrm{~d}$ and $7 \mathrm{e}$, respectively), shown in Moisidi et al. (2013). The ERT1 profile which was conducted west of the Basin (Fig.11) indicated:

- at about $90 \mathrm{~m}$ SSW of the ERT1 profile a NW to WNW-ESE striking fault zone (associated with $\mathrm{GH}$ zone, Fig.10) is indicated by sub-vertical changes in the resistivity (high resistive zone $>200$ Ohm•m and low resistive zone $<40 \mathrm{Ohm} \bullet \mathrm{m}$ ).

- the high resistive zone has a $20 \mathrm{~m}$ width and the fault zone can be followed from the surface down to $30 \mathrm{~m}$ depth.

- Moreover, along the sides of the profile the soil resistivity column from the surface down is locally characterized by resistivity variations of medium/high resistive layers overlying low resistive layers and vice-versa. Variations in the resistivity at depth occur either in horizontally stratified layers or along irregular inclined (highly angle and/or near vertical) stratification interfaces.

The ERT2 profile which was conducted to the northeast of the Basin (Fig.11) indicated: 
- a near vertical high resistive zone (at about $170 \mathrm{~m}$ west and $50 \mathrm{~m}$ east of the profile) striking to almost NS (associated with the fault zone EF, Fig.10). The high resistive $(<500 \mathrm{Ohm} \bullet \mathrm{m})$ zone has at least $30 \mathrm{~m}$ width and the fault zone can be followed from the surface down to $20 \mathrm{~m}$ depth.

- The width of the fault zone seems to broaden of at least $50 \mathrm{~m}$, below $20 \mathrm{~m}$ depth. Moreover, west of the profile at depth below $6 \mathrm{~m}$ the resistivity decreases (in horizontally stratified layers) from high $(<200 \mathrm{Ohm} \cdot \mathrm{m})$ to low values $(<10 \mathrm{Ohm} \cdot \mathrm{m})$, suggesting significant ground resistivity water content in sediments to a depth of $30 \mathrm{~m}$.

The ERT profiles show that the Basin is characterized by the following: steeply dipping faults, local decrease of the resistivity at depth indicated a significant water content of sediments at depth, resistivity variations either in horizontal or irregular interfaces, local variations in the thickness of the sedimentary deposits or in the grade of soil consolidation.

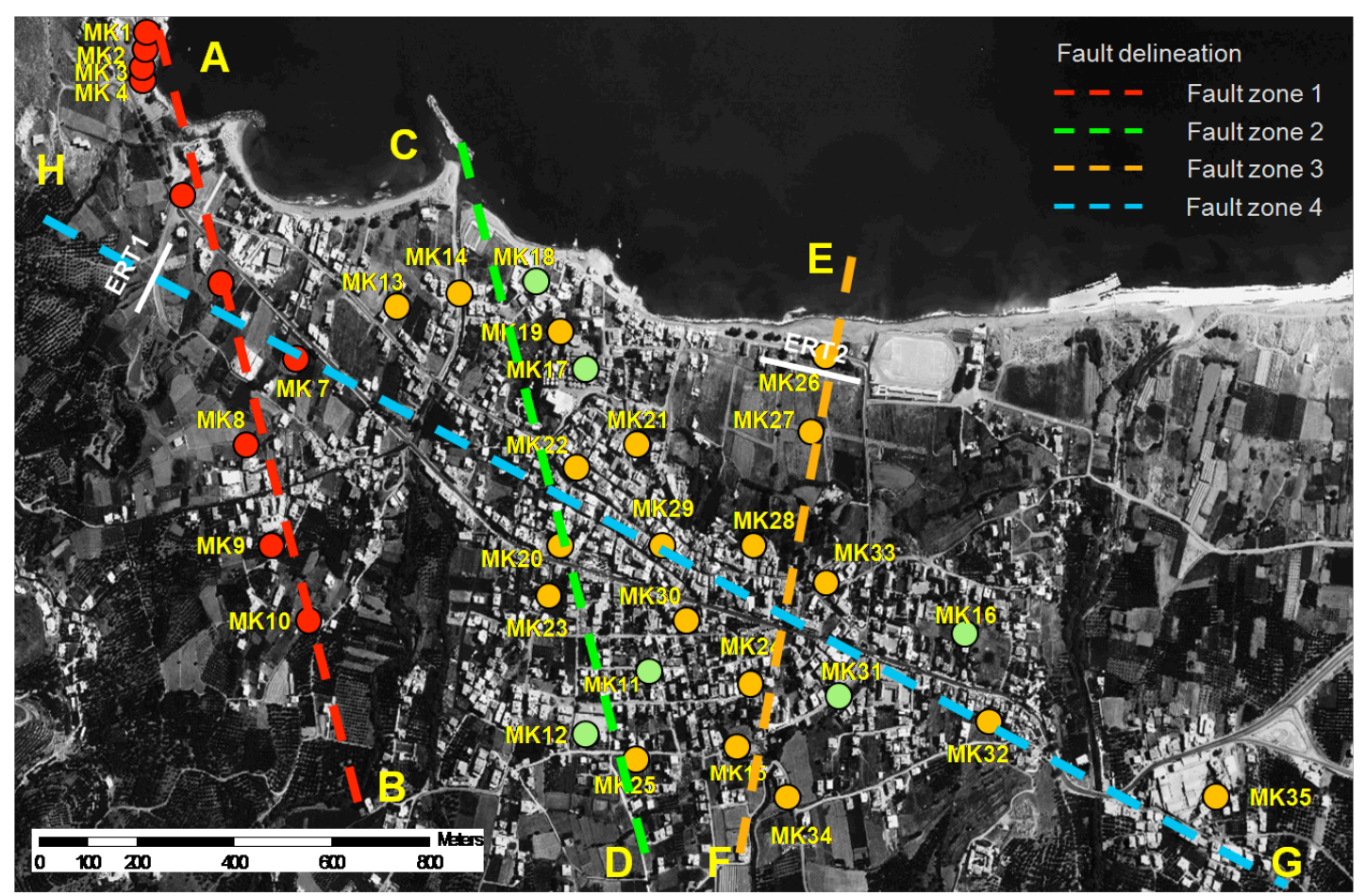

Fig.11 The fractured/fault zone delineation based on HVSR technique applied to microtremors incorporating into the sites of the ERT1 and ERT2 surveys conducted to verify the existence of faults along sections HG and EF. Along the profile ERT1 west of Kastelli a NW to WNW-ESE striking fault zone has been revealed. The fault has width of at least $20 \mathrm{~m}$ and the fault zone can be followed from the surface down to $30 \mathrm{~m}$ depth. Near surface resistivity variations to a depth of $25 \mathrm{~m}$ indicate highly inclined/dipping interface stratification. In the central Kastelli Basin along the ERT2 profile an almost NS striking fault zone is indicated by sub-vertical changes in the resistivity. The high resistive zone has at least $30 \mathrm{~m}$ width and the fault zone can be followed from the surface down to $20 \mathrm{~m}$ depth. The width of the fault zone broadens to at least $50 \mathrm{~m}$, below $20 \mathrm{~m}$ depth. The reader is referred to Moisidi et al. (2013) for the ERT surveys

For the Kastelli Basin we suggest that the aforementioned low HVSR amplitude could be related to the amplification of the vertical component likely attributed to: i) the high angle to near vertical fault zones may act as sources providing near vertical ray paths, ii) 2D/3D effects of the near subsurface (heterogeneities/irregularities/discontinuities or fault zones) structure, iii) to possible S-P conversion at the complex geological boundaries interfaces. Moreover, considering the network of near vertical fault zones we presume that the noise wave-field in addition to the local surface generated waves in the Basin contains a significant amount of $P$ waves. However, in the centre of the Basin we might have a combined effect of locally $\mathrm{P}$ to $\mathrm{S}$ mode conversion (affecting mainly the horizontal components of seismic motion) and $\mathrm{S}$ to $\mathrm{P}$ mode conversion (affecting the vertical components of seismic motion) along the geological 
interface as well as the effects of heterogeneities/irregularities of the near subsurface structure locally induced by high angle to near vertical fault zones providing near vertical ray paths.

Previous case studies have demonstrated that the low HVSR amplitude is associated with the amplification of the vertical component of motion which occurs due to several factors. Parolai and Richwalski (2004) applied H/V ratio on earthquake data and on synthetic seismograms in a layered three case studies medium and showed that the S-P conversion resulted in amplification of the vertical component in the S-wave window and deamplification in the $H / V$ ratio. Ameri et al. (2011) compared amplification and frequency derived from Generalized Inversion Technique (GIT) and from HVSR applied to earthquake and noise data for the case of L'Acquila (Italy) and found at some sites lower amplitude of HVSR compared to GIT. The observed lower amplification was ascribed to the amplification of the vertical component of motion due to S-P wave conversion, P-wave resonance in the earthquake data and to the local $2 \mathrm{D}$ topographic effects related to the morphological characteristics of the relief of the Castelnuovo village in Aterno valley (Italy). Strollo et al. (2011) for the case study of microzonation in Potenza (Italy) compared HVSR, SSR and GIT and found good correlation of the results while at one site the differences in the amplification was ascribed to the amplification in the vertical component. Bindi et al. 2009 applied time-frequency analysis in earthquake data recorded in Gubbio Basin (Italy) and showed the dispersive behavior of the large amplitudes arrivals after the S-waves which suggested the contribution of the locally generated Rayleigh waves in determining large ground motion amplitude of the vertical component. 2D/3D effects of the Gubbio Basin inserted locally generated Basin-induced waves which amplify the vertical component and affect the HVSR amplitude. Similarly, Bindi et al. (2011) related the presence of significant amplification affecting the vertical component to either the velocity inversion or to 2D/3D effects of the Norcia Basin (central Italy). Lewis et al. (2007) observed that head and direct $P$ waves are induced by the near vertical ray paths of San Andrea fault zone (California). Moreover, Ameri et al. (2011) suggested for the case study of L'Acquila earthquake that the sources-to-sites geometry is capable to imply a number of near vertical ray paths due to the location of most of stations just above the hypocenters. The research outcome extracted from the above studies indicate that the observed low amplification in the spectral ratios can be associated with the amplification of the vertical component of motion which can be induced by the velocity inversion, S-P conversions or by 2D/3D effects (heterogeneities/irregularities due to Basin effects or to fault zones).

For the small scale Kastelli-Kissamos Basin we assessed the delineation of four structures related to fractured and/or fault zones derived from the spatial spectral variations of microtremors (the presence of three of those zones $-\mathrm{AB}, \mathrm{EF}$ and $\mathrm{GH}$ - have been verified and cross-correlated from ground-truthed field evidence, geological map data and images extracted from ERT surveys). In addition, the ERT profiles have shown (Moisidi et al. 2013) steeply dipping faults, variations in the resistivity at depth which occur either in horizontal stratified layers or locally along complex irregular/inclined interfaces. The steeply dipping faults may act as sources providing near vertical ray paths and in addition the inferred 2D/3D effects and the complex geological interfaces may lead to S-P and P-S conversions. Moreover, considering the small scale Basin characterized by heterogeneities/irregularities/fault zones we can infer the following: a) the Rayleigh waves effects is highly prone to dominate in the wavefield of microtremor (this is a task for a future survey in Kastelli-Kissamos Basin), and b) the source to recording site geometry might be capable to infer near vertical ray paths (since microtremor recording station are installed at sites just above fault zones). Summarizing, for the Kastelli-Kissamos Basin the factors that can amplify the 
vertical component of motion and consequently to affect the HVSR amplitude are: the velocity inversion, S$\mathrm{P}$ conversions, 2D/3D effects, near vertical ray paths induced by the identified steeply dipping fault zones.

For the Kastelli-Kissamos Basin we observe that the sites of HVSR peaks slightly below 2.0 are spread among sites of HVSR amplitude beyond 2.0. The results allow us to infer that the amplitude quality criteria of $A>2$ proposed by Sesame might be too restricted since neighboring sites presenting stability in the HVSR shape and frequencies show HVSR peak slightly below and beyond 2.0. Suggestions that the amplitude clarity criteria of $A>2$ might be too restricted have been also mentioned by Bonnefoy-Claudet et al. (2008) and Pilz et al. (2009).

This site effects study in Kastelli Basin was the first exploratory analysis to determine near subsurface structure using the spectra of ambient noise measurements. Considering the small scale Kastelli Basin and the complex near heterogeneities of the structure locally related to fault zones crosscutting the dense populated area we discriminate soil conditions of the Basin into category $X$ according to the Greek Seismic Code 2000 (EAK 2000).

The complex near subsurface structure of Kastelli Basin (Kissamos, NW Crete) patterned in HVSR curves provides a task for future research surveys involving a variety of geotechnical engineering aspects and research issues such as numerical studies and building damage scenarios (recently, Chiauzzi et al. 2011 have estimated building damage scenarios based on Housner spectral intensity derived from finite fault ground motion simulations). In terms of local site amplification future research may include also strong motion data and comparison with different site effect techniques. A future survey may involve rock mass classification systems studies used by civil engineering (Waltham 2002) that have potential to verify the relation of fracture conditions and rating and to contribute to a detailed seismic hazards assessment for the Kastelli-Kissamos Basin.

In this study we did not focus on the discrimination between inactive and active faults, available by field observation (which cannot be done so easily in the case of buried faults) or by seismicity studies. However, the importance in seismic hazards studies is the fault zone delineation, since either active or inactive faults can behave as wave-guides in an impinging seismic wave front (Cornier and Spudich 1984) and in addition a previously inactive fault may become active during an earthquake. Structural building vulnerability techniques including possible soil-site resonance phenomena and building damage scenarios are essential to be conducted considering the complex near subsurface structure of the Basin characterized of a network of fault zones crosscutting the dense populated Kastelli - Kissamos Basin in northwest Crete.

\section{Conclusions}

For the purpose of site effects study of the small scale Kastelli Basin (Kissamos, NW Crete) we performed ambient noise vibration measurements. This work is the first site response study in the Basin. The spatial HVSR resonance pattern in the center of the Basin was characterized (in different sites) by one amplified and of two amplified peaks attributed to the surface and near subsurface structure. Sites of one HVSR amplified peak at low frequencies were related to soft or thick Quaternary deposits, in agreement with the geological data. The one amplified HVSR peak at medium frequencies was attributed to the spectral effects of the near subsurface heterogeneities, irregularities or discontinuities related to a fractured/fault zone. The two amplified peaks were attributed to the near subsurface heterogeneities/irregularities and to the overlying stratum of Quaternary deposits. The amplified peak at medium or high frequency was 
correlated with local heterogeneities/irregularities highly prone to be induced by the presence of fractured/fault zones of the near surface while the amplified peak at low frequencies was related with the overlying Quaternary deposits. Spatial spectral variability in the frequency and shape of the HVSR (one amplified peak at medium frequency and two amplified peaks with the one peak at low and the other either at medium or high frequencies) was capable to delineate four structures striking NNW, NNE and in a sector NW to WNW crosscutting the dense populated Basin. Three of the four fault zones have been verified incorporating into the ground-truthed field evidence, geological map data and images extracted from ERT surveys, suggesting that the HVSR technique using microtremors can be a valuable tool or at least an approximation for the near fault zone delineation for the Kastelli (Kissamos) Basin. In this study neighboring sites presenting HVSR amplitude slightly below and beyond 2.0, show stability in the HVSR shape and frequencies. We highlight the importance of fault zone delineation in earthquake damage distribution considering the intense seismic activity that can occur in this area. The spatial variations of microtremors, the identified frequencies in the range of engineering interest and the delineated fault zones can contribute, among to further multidisciplinary approaches, to future seismic hazards analysis for damage scenarios and seismic hazards assessment studies.

\section{Acknowledgments}

Margarita Moisidi was sponsored by the Greek State Scholarships foundations.

\section{References}

Ameri G, Oth, A, Pilz M , Bindi D, Parolai S, Luzi L, Mucciarelli M, Cultrera G (2011) Separation of source and site effects by generalized inversion technique using the aftershock recordings of the 2009 L'Aquila earthquake. Bull Earthquake Eng 9:717-739

Bard PY (1998) Microtremor measurements: a tool for site effect estimation?, In Proceedings of the Second International Symposium on the Effects of Surface Geology on Seismic Motion 3: 1251-1279

Bard PY and SESAME European research project WP12 (2004) Guidelines for the implementation of the $\mathrm{H} / \mathrm{V}$ spectral ratio technique on ambient vibrations: measurements, processing and interpretations, Deliverable D23.12 European Commission Research General Directorate Project No. EVG1-CT-200000026 SESAME

Beroya MAA, Aydin A, Tiglao R, Lasala M (2009) Use of microtremor in liquefaction hazard mapping. Eng Geology 107:140-153

Bonnefoy-Claudet S, Baize S, Bonilla LF, Berge-Thierry C, Pasten C, Campos J, Volan P, Verdugo R (2008) Site effect evaluation in the basin of Santiago de Chile using ambient noise measurements. Geophys J Int. doi: 10.1111/j.1365-246X.2008.04020.x

Bour M, Fouissac D, Dominique P, Martin C (1998) On the use of microtremor recordings in seismic microzonation. Soil Dyn Earthq Eng 17:465-474

Bindi D, Parolai S, Cara F, Di Giulio G, Ferretti G, Luzi L, Monachesi G, Pacor F, Rovelli A (2009) Site Amplifications Observed in the Gubbio Basin, Central Italy: Hints for Lateral Propagation Effects. Bull Seismol Soc Am 99: 741-760. doi: 10.1785/0120080238

Bindi D, Luzi L, Parolai S, Di Giacomo D, Monachesi G (2011) Site effects observed in alluvial basins: the case of Norcia (Central Italy). Bull Earthquake Eng 9:1941-1959. doi: 10.1007/s10518-011-9273-3

Calderoni G, Rovelli, A, Di Giovambattista R (2010) Large amplitude variations recorded by an on fault seismological station during the L'Aquila earthquakes:evidences for a complex fault induced site effect. Geophys Res Lett 37:L24305. doi:10.1029/2010GL045697

Cara F, Di Giulio G, Rovelli A (2003) A study on seismic noise variations at Colfiorito, central Italy: implications for the use of $\mathrm{H} / \mathrm{V}$ spectral ratios. Geophys Res Lett 30 (18)

Chavez-Garcia FJ, Guenca G, Sanchez-Sesma FJ (1995) Site effects in Mexico City urban zone, A complementary Study. Soil Dyn Earthq Eng 15: 141-146

Cornou C, Bard PY, Dietrich M (2003) Contribution of dense array analysis to identification and quantification of basin-edge induced waves, part II: Application to the Grenoble basin (French Alps). Bull Seism Soc Am 93:2624-2648

Chiauzzi L, Masi A, Mucciarelli M, Vona M, Pacor F, Cultrera G, Gallovic F, Emolo A (2011) Building damage scenarios based on exploitation of Housner Intensity derived from finite faults ground motion simulations Bull Earthquake Eng. doi10.1007/s10518-011-9309-8 
Cornier V, Spudich P (1984) Amplification of ground motion and waveform complexity in fault zones: examples from the San Andreas and Calaveras fault zones. Geophys J R Astronom Soc 79:135-152

Di Giacomo D, Gallipoli MR, Mucciarelli M, Parolai S, Richwalski S (2005) Analysis and modelling of HVSR in the presence of a velocity inversion. The case of Venosa (Italy). Bull Seism Soc Am 95: 2364-2372

EAK 2000, Greek code for the Seismic Resistant structures, Organization for Earthquake Resistant Planning and Protection, Ministry of Environment Planning and Public Works, Greece (OASP)

Fäh D 1997 Microzonation of the city of Basel. J Seismol 1: 87-102

Field EH, Jacob KH (1995) A Comparison and Test of Various Site Response Estimation Techniques, Including Three That Are Not Reference Site Dependent. Bull Seismol Soc Am 85:1127-1143

Field EH, Clement AC, Jacob SM, Aharonian V, Hough SE, Friberg PA, Babaian TO, Karapetian SS, Hovanessian SM, Abramian HA (1995) Earthquake site-response study in Giumri (formely Leninakan), Armenia, using ambient noise observations. Bull Seismol Soc Am 85:349-353

Gallipoli MR, Albarello D, Mucciarelli M, Bianca M (2011) Ambient noise measurements to support emergency seismic microzonation: the Abruzzo 2009 experience. Bollettino di Geofisica Teorica ed Applicata 52: 539-559. doi: 10.4430/bgta0031

Giampiccolo E, Gresta S, Mucciarelli M, De Guidi G, Gallipoli MR (2001) Information on subsoil geological structure in the city of Catania (Eastern Sicily) from microtremor measurements. Annali di Geofisica 44:1-11

Gosar A (2007) Microtremor HVSR study for assessing site effects in the Bovec basin (NW Slovenia) related to $1998 \mathrm{Mw} 5.6$ and $2004 \mathrm{Mw} 5.2$ earthquakes. Engineering Geol 91:178-193

Gueguen P, Chatelain JL, Guillier B, Yepes H (2000) An indication of the soil topmost layer response in Quito (Ecuador) using noise H/V spectral ratio. Soil Dyn Earthquake Eng 19:127-133

Gueguen P, Cornou C, Garambois S, Banton J ( 2007) On the limitation of the H/V spectral ratio using seismic noise as an exploration tool: application to the Grenoble valley (France), a small apex ratio basin. Pure Appl Geophys 164:115-134

Horike M, Zhao B, Kawase H (2001) Comparison of site response characteristics inferred from microtremor and earthquake shear waves. Bull Seismol Soc Am 91:1526-1536

Institute for Geology and Subsurface Research (IGSR) 1970 Geological map of Greece, Kastelli Sheet (Geological survey conducted by Karageorgiou E, 1:50.000 scale)

Institute of Geology and Mineral Exploration (IGME) 2002 Geological map of Greece, Paleohora Sheet (Geological survey conducted by Tsalahouri E and Fontou C 1:50.000 scale)

Konno K and Ohmachi T (1998) Ground-motion characteristics estimated from spectral ratio between horizontal and vertical components of microtremor. Bull Seismol Soc Am 88:228-241

Lebrun B, Hatzfeld D, Bard P.Y (2001) Site effect study in urban area: experimental results in Grenoble (France). Pure Appl Geophys 158: 2543-2557

Lewis MA, Peng Z, Ben-Zion Y, Vernon F L (2005) Shallow seismic trapping structure in the San Jacinto fault zone near Anza, California. Geophys J Int 162:867-881

Lewis MA, Ben-Zion Y, McGuire JJ (2007) Imaging the deep structure of the San Andreas Fault south of Hollister with joint analysis of fault zone head and direct P arrivals. Geophys J Int 169: 1028-1042

Lombardo G, Rigano R (2006) Amplification of ground motion in fault and fractures zones: Observations from the Tremestieri faults MT Etna (Italy). J Vulcan and Geotherm Res 153:167-176

Marzorati S, Ladina C, Falcucci E, Gori S, Saroli M, Ameri G, Galadini F (2011) Site effects "on the rock": the case of Castelvecchio Subequo (L'Aquila, central Italy). Bull Earthquake Eng 9:841-868. doi 10.1007/s10518-011-9263-5

McKenzie DP (1978) Active tectonics of the Alpine-Himalayan belt: the Aegean Sea and surrounding regions. Geophys J R Astron. Soc 55:217-254

Meier T, Becker D, Endrun M, Rische M, Bohnhoff M, Stöckhert B, Harjes HP (2007) A model for the Hellenic subduction zone in the area of Crete based on seismological investigations. Geol Soc London, Special Publications 291: 183-199

Moisidi M 2009 Geological geophysical and seismological investigations for earthquake hazards estimation in western Crete Phd Thesis Dissertation, Brunel University London $842 \mathrm{pp}$

Moisidi M, Vallianatos F, Soupios P, Kershaw S (2012) Spatial spectral variations of microtremors and electrical resistivity tomography surveys for fault determination in southwestern Crete, Greece. J Geophys Eng 9:261-270. doi:10.1088/1742-2132/9/3/261

Moisidi M, Vallianatos F, Soupios P, Kershaw S, Rust D, Piscitelli S (2013) Modeling tectonic features of the Kissamos and Paleohora areas, Western Crete (Greece): combining geological and geophysical surveys. J Geophys Eng 10: 1-17. doi:10.1088/1742-2132/10/2/025015

Mucciarelli M (1998) Reliability and applicability range of the Nakamura's technique using microtremors An experimental approach. J Earthq Eng 2: 625-638

Mucciarelli M and Monacheri G (1998) A Quick survey of local amplifications and their correlation with damage observed during the Umbro-Marchesan (Italy) earthquake of September 26, 1997. J Earthq Eng 2: 325-337 
Mucciarelli M, Monacheri G, Gallipoli, MR (1999) In situ measurements of site effects and building dynamic behaviour related to damage observed during the 9/9/1998 earthquake in Southern Italy In: Proc. Of ERES1999 Conference, Catania, Italy 253-265

Mucciarelli M, Masi A, Vona M, Gallipoli MR, Harabaglia P, Caputo R, Piscitelli S, Rizzo E, Picozzi M, Albarello D, Lizza C (2003a) Quick survey of the possible causes of damage enhancement observed in San Giuliano after the 2002 Molise, Italy, seismic sequence. J Earthq Eng 7: 599-614

Mucciarelli M, Gallipoli MR, Arcieri M (2003b) Stability of Horizontal-to-Vertical Spectral Ratio by triggered noise and earthquake recordings. Bull Seismol Soc Am 93:1407-1412

Mucciarelli M, Gallipoli M, Di Giacomo D, Di Nota F, Nino E (2005) The influence of wind on measurements of seismic noise. Geophys J Int 161:303 -308

Mucciarelli M (2011) Ambient Noise Measurements following the 2011 Christchurch Earthquake: Relationships with Previous Microzonation Studies, Liquefaction, and Nonlinearity. Seismol Res Lett 82: 919-926

Mucciarelli M, Bianca M, Ditommaso R, Vona M, Gallipoli MR, Giocoli A, Piscitelli S, Rizzo E, Picozzi M (2011) Peculiar earthquake damage on a reinforced concrete building in San Gregorio (L'Aquila, Italy): site effects or site defects ?. Bull Earthquake Eng 9:825-840. doi: 10.1007/s10518-011-9257-3

Nakamura Y (1989) A method for Dynamic Characteristics Estimation of Subsurface using Microtremor on the Ground surface, Quarterly Report of RTRI, Railway Technical Research Institute 30:25-30

Nakamura Y (1996) Real Time Information systems for seismic Hazards Mitigation UREDAS, HERAS, PIC, Quarterly Report of RTRI 37 (3)

Nakamura Y (2000) Clear identification of fundamental idea of Nakamura's method for dynamic characteristics estimation of subsurface using microtremor on the ground surface and its applications, Proceedings of the 12th World Conference on Earthquake Engineering, Auckland, New Zealand

Nogoshi M and Igarashi T (1971) On the amplitude characteristics of microtremor, Part 2 (In Japanese with English abstract. J Seismol Soc Japan 24:26-40

Nguyen F, van Rompaey G, Teerlynck H, Van Camp M, Jongmans D, Camelbeeck T (2004) Use of microtremor measurement for assessing site effects in Northern Belgium-interpretation of the observed intensity during the Ms=5.0 June 11, 1938 Earthquake. J Seismol 8:41-56

Oros E (2009) Site effects investigation in the city of Timisoara using spectra ratio methods., 2009. Rom Rep Physics 61:347-358

Özalaybey S, Zor E, Ergintav S, Tapırdamaz C (2011) Investigation of 3-D basin structures in the 'Izmit Bay area (Turkey) by single-station microtremor and gravimetric methods, Geophys J Int 186:883-894

Papazachos BC, Karakostas VG, Papazachos CB, Scordilis EM (2000) The geometry of the WadattiBenioff zone and lithospheric kinematics in the Hellenic arc. Tectonophys 319:275-300

Parolai S and Richwalski SM (2004) The Importance of Converted Waves in Comparing H/V and RSM Site Response Estimates. Bull Seism Soc Am 94:304-313

Parolai S, Richwalski SM, Milkereit C, Bormann P (2004) Assessment of the stability of H/V spectral ratios from ambient noise and comparison with earthquake data in the Cologne area (Germany). Tectonophysics 390:57-73

Pilz M, Parolai S, Leyton F, Campos J, Zschau J (2009) A comparison of site response techniques using earthquake data and ambient seismic noise analysis in the large urban areas of Santiago de Chile. Geophys J Int 178:713-728

Pirazzoli PA, Thommeret J, Thommeret Y, Laborel J, Montag-Gioni LF (1982) Crustal block movements from Holocene shorelines: Crete and antikythira (Greece). Tectonophys 86:27-43

Puglia R, Ditommaso E, Pacor F, Mucciarelli M, Luzi L, Bianca M (2011) Frequency variation in site response as observed from strong motion data of the L'Aquila (2009) seismic sequence. Bull Earthquake Eng 9:869-892

Rodriguez HS and Midorikawa S (2002) Applicability of the H/V spectral ratio of microtremors in assessing site effects on seismic motion. Earthq Eng Structural Dyn 31:261-279

Roten D, Fäh D, Olsen KB, Giardini D (2008) A comparison of observed and simulated site response in Rhône valley. Geophys J Int 173: 958-978

Stiros SC and Papageorgiou S (2001) Seismicity of Western Crete and the destruction of the town of Kisamos at AD 365: Archaeological evidence. J Seismol 5:381-397

Strollo A, Parolai S, Bindi D, Chiauzzi L, Pagliuca P, Mucciarelli M, Zschau J (2011) Microzonation of Potenza (Southern Italy) in terms of spectral intensity ratio using joint analysis of earthquakes and ambient noise. Bull Earthquake Eng. doi: 10.1007/s10518-011-9256-4

Teves-Costa P, Matias L, Bard PY (1996) Seismic Behaviour estimation of thin alluvium layers using microtremors recordings. Soil Dyn Earthq Eng 15:201-209

Volant Ph, Orbovica N, Dunandb F (2002) Seismic evaluation of existing nuclear facility using ambient vibration test to characterize dynamic behavior of the structure and microtremor measurements to characterize the soil: a case study. Soil Dyn Earthq Eng 22: 1159-1167

Waltham T (2002) Foundations of Engineering Geology, Second edition, Spon Press 104 pp 